\title{
Noise attenuation and communication enhancement characteristics of the USCG boat crew communication system
}

Jeffrey S. Clark

West Virginia University

Follow this and additional works at: https://researchrepository.wvu.edu/etd

\section{Recommended Citation}

Clark, Jeffrey S., "Noise attenuation and communication enhancement characteristics of the USCG boat crew communication system" (2008). Graduate Theses, Dissertations, and Problem Reports. 4362. https://researchrepository.wvu.edu/etd/4362

This Thesis is protected by copyright and/or related rights. It has been brought to you by the The Research Repository @ WVU with permission from the rights-holder(s). You are free to use this Thesis in any way that is permitted by the copyright and related rights legislation that applies to your use. For other uses you must obtain permission from the rights-holder(s) directly, unless additional rights are indicated by a Creative Commons license in the record and/ or on the work itself. This Thesis has been accepted for inclusion in WVU Graduate Theses, Dissertations, and Problem Reports collection by an authorized administrator of The Research Repository @ WVU. For more information, please contact researchrepository@mail.wvu.edu. 
Noise Attenuation and Communication Enhancement Characteristics of the USCG Boat Crew Communication System

\author{
Jeffrey S. Clark
}

\begin{abstract}
Thesis submitted to the College of Engineering and Mineral Resources

at West Virginia University in partial fulfillment of the requirements

for the degree of

Master of Science

in

Industrial Hygiene

\author{
Steven Guffery, Ph.D., Chair \\ Kevin Rider, Ph.D. \\ Mohammed Virji, Ph.D. \\ Department of Industrial and Management \\ Systems Engineering
}

Morgantown, West Virginia

2008 


\begin{abstract}
Noise Attenuation and Communication Enhancement Characteristics of the USCG Boat Crew Communication System
\end{abstract}

Jeffrey S. Clark

The US Coast Guard is prototyping a new small boat communication system which consists of the MSA Sordin Supreme Pro headset in combination with a wireless communications system. The MSA Sordin headset receives wireless communications input independently from an amplitude-sensitive sound transmission feature which amplifies ambient noise in certain frequency ranges. The purpose of this study was to determine the extent to which the communication system improves speech intelligibility in noise and to measure the noise reducing capabilities of the headset with the amplification feature activated and with it turned off. Overall noise reduction was calculated based on four different noise spectrums to compare actual noise reduction to the manufacturer advertised Noise Reduction Rating (NRR). Additionally, clamp force was measured to determine its relationship with noise reduction. This study found that the communication system, consisting of wireless communications and the activated headset amplification feature, drastically improved verbal communications when compared to the case of the headset donned but wireless communication disconnected and headset amplification off ( $88 \%$ vs $44 \%$ intelligibility score in 90 dBA background noise; $82 \%$ vs negligible intelligibility in $100 \mathrm{dBA}$ background noise). The MSA Sordin headset amplification feature had a profound effect on the hearing protector's noise reducing capability. When it was activated, noise reduction was dramatically lower in all frequencies above $315 \mathrm{~Hz}$. This resulted in lower overall noise reduction when this feature was on. Mean overall noise reduction values ranged from 11.2 to $27 \mathrm{dBA}$ with the amplification feature turned off and 6.7 to $0.2 \mathrm{dBA}$ with the amplification feature activated. The difference was least in low frequency dominant noise (11.2 vs $6.7 \mathrm{dBA})$ and greatest in high frequency dominant noise ( $27 \mathrm{vs} 0.2 \mathrm{dBA})$. The low frequency dominant spectrum used in this study was recorded onboard an operational USCG 47' Motor Life Boat, the system's intended operating environment. In this intended environment, the calculated overall noise reduction was less than the manufacturer advertised rating of $18 \mathrm{~dB}$ (study values; $11.2 \mathrm{dBA}$ without amplification, 6.7 dBA with amplification). A weak positive correlation was found between clamp force and noise reduction but the association was not statistically significant, meaning that clamp force was not the reason for the noise reduction performance of the MSA Sordin headset. 


\section{Table of Contents}

Subject

Abstract

Page

Introduction

Background

Apparatus

Methods

Results and Discussion $\quad 19$

Conclusion $\quad 34$

Limitations $\quad 34$

Recommendations $\quad 35$

References $\quad 36$

Appendix A. Sample Calculations and Tables 38

Appendix B. Data Tables and Figures with Subject 7 included 39

Appendix C. Hearing in Noise Test Sentence Lists 41

Tables and Figures

Table 1. $\mathrm{OB}_{98}$ Calculation for Low Frequency Dominant Noise Spectrum

Table 2. $\mathrm{OB}_{98}$ Calculation for High Frequency Dominant Noise Spectrum

Page

Table 3. Manufacturer Hearing Protector Data 16

Table 4. Speech Intelligibility Scores 20

Table 5. Statistical Analysis of Overall Attenuation Values - MSA Sordin Headset, Amplification Off (without Subject 7) 27

Table 6. Statistical Analysis of Overall Attenuation Values - Peltor H10A $\begin{array}{ll}\text { Earmuff } & 28\end{array}$

Table 7. MSA Sordin Supreme Pro Headset Octave Band Noise Reduction 29

Table 8. MSA Sordin/Clamp Force Analysis 32

Table 9. Peltor/Clamp Force Analysis 33

Table A1. NRR Calculations - Manufacturer Data 38

Table A2. Noise Reduction Calculations: Unweighted, C-Weighted, A-Weighted and Octave Band Method (NIOSH Method \#1) using 47 footMLB Noise Spectrum with Manufacturer Data 38

Table B1. Noise Reduction Values in Pink Noise Spectrum 40

Table B2. Noise Reduction Values in Field Measured 47 footMLB Noise Spectrum

Table B3. Statistical Analysis of Overall Attenuation Values - MSA Sordin

Figure 1. Peltor Twin Cup H10A Manufacturer Noise Reduction Data 7

Figure 2. Low and High Frequency Dominant Noise Fields 8

$\begin{array}{lr}\text { Figure 3. Nagra ARES-PII+ } & 12\end{array}$

Figure 4. Reverberation Chamber 12

Figure 5. Europower Amplifiers $\quad 12$

Figure 6. OROS OR38 Multi-analyzer 13 
$\begin{array}{lr}\text { Figure 7. Microphones } & 13\end{array}$

Figure 8. Clamp Force Indicator 13

Figure 9. Speech Intelligibility - Communications Off 15

Figure 10. Speech Intelligibility - Communications On 15

Figure 11. Speech Intelligibility Scores $\quad 19$

Figure 12. Hypothetical Pink Noise vs. Actual Pink Noise 21

Figure 13. MLB Noise Spectrum Corrected vs. Field Measured Spectrum 22

Figure 14. MSA Sordin on the Left, Peltor on the Right 22

Figure 15. Noise Reduction: Amplification On vs. Amplification Off (Without $\begin{array}{ll}\text { Subject 7) } & 23\end{array}$

Figure 16. MSA Sordin Noise Reduction: Study Data vs. Manufacturer - Headset Amplification Off (without Subject 7) 24

Figure 17. Peltor H10A Noise Reduction: Study Data vs. Manufacturer 25

Figure 18. MSA Sordin Headset: Noise Reduction vs. Clamp Force 31

Figure 19. Peltor H10A: Noise Reduction vs. Clamp Force 31

Figure B1. Mean Noise Reduction: Headset Amp on vs. Headset Amp Off (with Subject 7) 39

Figure B2. Noise Reduction: Study Data vs. Manufacturer - Headset Amplification Off (with Subject 7) 


\section{Introduction}

Passive Hearing Protection Devices (HPDs) have been used extensively since the 1950's to limit noise exposure. Despite this workers have frequently cited negative effects on communication as one of the primary reasons for not wearing hearing protection (Howell and Martin, 1975). In response to the challenge of providing adequate hearing protection without degrading intelligibility, special HPDs have been developed which will attenuate ambient noise while improving auditory perception and speech communications.

The United States Coast Guard (USCG) faced these challenges when deploying the service's newest and most sophisticated Motor Lifeboat (MLB). The MLB has traditionally always been the workhorse of USCG coastal rescue stations, performing all of the USCG's primary missions of search and rescue, law enforcement, maritime security, and defense operations (Krietmeyer, 1991). Noise exposure is nothing new to the men and women of the USCG. On prior incarnations of USCG MLBs, the crew could at least escape engine noise on the bridge were communications were relatively unimpeded, but the new 47 foot MLB is so powerful and compact that the noise level is intense and concentrated, thereby constituting both an exposure risk and an impediment to communications. Safety and health evaluations found that the ambient noise environment routinely surpassed the USCG threshold level of 85 dBA-TWA (USCG, 1990). Even radio communications with land based stations or other sea or air assets were degraded, severely reducing operational effectiveness in coordinated operations (USCG, 2002).

\section{Boat Crew Communications System}

Concerns over crew member exposure to harmful levels of noise along with the desire to maximize operational performance led the USCG to allocate funding for the research and development of a Boat Crew Communication System (BCCS). The primary goals of the system are to improve communications among boat crew members conducting operations and to reduce noise exposure while not encumbering the crew. The primary requirements were safe operability, durability in harsh environments, Noise Reduction Rating (NRR) of $20 \mathrm{dBA}$, wireless communications, and compatibility with USCG equipment (USCG, 2006). The proposed system combines wireless intercom communications with noise reduction capability utilizing the MSA-Sordin Supreme Pro \#75302 headset. In addition to wireless communications, the headset incorporates microphones and amplifiers to transmit ambient sound to the earphones mounted inside the headset (hereafter referred to as the headset amplification feature).

When the USCG tests and evaluates the BCCS in the field, most of the testing will be subjective, based on crew members observations of utility, usability and protection. However, certain aspects of the test and evaluation plan can be objectively tested in the laboratory, including the actual noise attenuation of the headset at the ear as well as the expected enhancement of verbal communication. 


\section{Purpose of this Study and Hypotheses}

The overall objectives of this study are to determine the effectiveness of the communication system and its capacity to protect workers from noise exposure in its intended environment and for other selected environments with varying noise spectra. In particular will the electronic communication features actually improve verbal intelligibility in noise? What effect will the headset amplification feature have on the noise reducing capability of the MSA Sordin headset? Will headset clamp force have an effect on the noise reduction capability of the headset, and will the noise reduction measured in this study, under simulated field conditions, differ from the noise reduction data provided by the manufacturer?

This study will test the following hypotheses:

1) $\quad \mathrm{H}_{0}: \mathrm{INT}_{\text {with comms }}=\mathrm{INT}_{\text {without comms }}$

$\mathrm{H}_{1}: \mathrm{INT}_{\text {with comms }}>\mathrm{INT}_{\text {without comms }}$

where: $\mathrm{INT}=$ intelligibility score

with comms = with microphone/amplification systems activated

without comms $=$ with the microphone/amplification systems deactivated

2) $\mathrm{H}_{0}: \mathrm{NR}_{\mathrm{amp} \mathrm{on}}=\mathrm{NR}_{\mathrm{amp} \mathrm{off}}$

$\mathrm{H}_{1}: \mathrm{NR}_{\mathrm{amp} \text { on }} \neq \mathrm{NR}_{\mathrm{amp} \mathrm{off}}$

where: $\mathrm{NR}_{\mathrm{amp} \mathrm{on}}=$ noise reduction, headset amplification feature activated

$\mathrm{NR}_{\mathrm{amp} \mathrm{off}}=$ noise reduction, headset amplification feature deactivated

3) $\mathrm{H}_{0}: \mathrm{OB}=\mathrm{NRR}$

$\mathrm{H}_{1}: \mathrm{OB}<\mathrm{NRR}$

where: $\mathrm{OB}=$ Octave Band method overall noise reduction

$\mathrm{NRR}=$ Environmental Protection Agency (EPA) noise reduction rating.

4) $\mathrm{H}_{0}: \mathrm{NR}=$ constant

$\mathrm{H}_{1}: \mathrm{NR}=\mathrm{f}\{$ clamp force $\}$

where: clamp force $=$ compression force of the earmuff type hearing protector 


\section{Background}

The goals of this study were to determine the noise attenuation capability of the MSA Sordin headset, determine whether noise reduction was a function of clamp force, and to measure the extent to which the headset improves or impedes verbal communication.

Over the last fifty years many studies have been conducted to determine the attenuation characteristics of HPDs. The studies have focused on three general areas: 1) the effectiveness of HPD attenuation when compared to manufacturer NRR data (Behar, 1985; Berger et al., 1996; Stewart, 2000), 2) which devices perform the best (i.e., earplug vs. earmuffs), and 3) the effects of HPD attenuation on communication (Berger, 2003; Howell and Martin, 1975; Wagoner et al., 2007). Several studies have also been conducted to study the difference between lab attenuation values and actual attenuation in the field (Casali and Park, 1991; Casali and Grenell, 1989). One of the key issues at the heart of these studies is the measurement of actual HPD attenuation and the methodology to accurately determine the noise attenuating characteristics of HPDs.

\section{REAT Method}

The Real-Ear Attenuation at Threshold (REAT) method is considered the "gold standard" for measuring the noise reduction of any passive hearing protector. The method was promulgated by the American National Standards Institute (ANSI, 1974). Many studies have utilized the REAT method to determine HPD attenuation (Berger, 1983; Casali et al., 1995; Wagoner et al., 2007). The REAT is a psychophysical (real-ear, sensationbased) technique which measures the difference between the minimum sound level an individual can perceive without the HPD and the minimum level detectable with the hearing protector on. This difference, the Insertion Loss (IL), is the attenuation provided by a hearing protector:

$$
I L(d B)=S P L_{\text {ear }}-S P L_{\text {ear }}
$$

where: IL is the insertion loss in decibels

$\mathrm{SPL}_{\text {ear }}$ is the detectable sound pressure level without the HPD

$\mathrm{SPL}_{\text {ear }}$ is the detectable sound pressure level with the HPD.

The EPA specifies the REAT method for obtaining the noise reduction data required to calculate the NRR (EPA, 1979).

The REAT has disadvantages which led to the development of alternative techniques to determine noise reduction. One is that the test environment must be strictly controlled since the IL determination requires two measurements (with and without the HPD). Accurate interpretation requires recording occluded and unoccluded measurements with the same signal (i.e., operating mode, spectrum shape and noise level) at each frequency center band. This is not a problem in a controlled laboratory setting, but this level of control would be difficult to achieve in a field environment. Another disadvantage of REAT is the masking of occluded thresholds by physiological noise at low frequencies 
(Casali et al., 1995; Berger, 2003). Physiological noise (from skull, canal wall and concha/pinna vibrations) arises from respiration, heart beat/blood flow, and muscle tremor. It is primarily a low-frequency phenomenon, occurring below $250 \mathrm{~Hz}$ and is amplified by the occlusion effect much like any other low-frequency vibratory influence (Berger and Kerivan, 1983). At low frequencies, the amplified, physiological noise masks the REAT signal until the sound pressure is raised to a sufficient level to overcome the masking. This creates the overestimation of attenuation, since without the masking effects, the occluded threshold would be reached at a lower sound level.

\section{MIRE Method}

The Microphone in Real Ear (MIRE) test is an objective method which overcomes these two obstacles. Instead of relying on the subject's sensation-based thresholds, the actual sound pressure level is physically measured at the entrance of the ear canal (SPLear). For $\mathrm{IL}, \mathrm{SPL}_{\text {ear }}$ is measured with and without the protector. This overcomes the physiological noise induced contamination which can occur with REAT. Since MIRE measurements are not sensation based, a quiet environment is not required.

In addition, MIRE allows for simultaneous noise measurements, requiring less time than REAT and ensuring measurement of equivalent noise. For these reasons the MIRE methodology is an ideal candidate for field study (Berger, 2003). The simultaneous method involves taking readings inside and outside the protector at the same time, yielding a measure of Noise reduction (NR) as opposed to the IL:

$$
N R(d B)=S P L_{\text {ambient }}-S P L_{\text {ear }}
$$

Equation (2)

where: NR is the noise reduction

$\mathrm{SPL}_{\text {ambient }}$ is the level outside the HPD

$\mathrm{SPL}_{\text {ear }}$ is the level inside the HPD

For all of its advantages, utilizing the MIRE/NR methodology presents one disadvantage when compared to IL measurements. A direct conversion of NR to IL can not be done without applying a correction factor to account for the Transfer Function of the Open Ear (TFOE), a physiological effect that increases the sound level from outside the ear to the entrance of the ear canal (Casali et al., 1995). This increase, due to resonance and diffraction effects, results in NR values which underestimate attenuation by the amount of the TFOE:

$$
I L(d B)=N R+T F O E
$$

where: IL is insertion loss

$\mathrm{NR}$ is the noise reduction

TFOE is the transfer function of the open ear

In Berger's 1986 review of methods to measure HPD attenuation, he states that IL is a more relevant metric of the performance of an HPD as it measures the difference between 
the sound pressure level reaching the open ear canal and the attenuated sound pressure level at the same location with HPD (Berger, 1986).

\section{The Noise Reduction Rating (NRR)}

The Noise Control Act passed by Congress in 1972 mandated the EPA to rate HPDs using the NRR method. The NRR is an attenuation index that represents the overall average noise reduction, in decibels, that an HPD will provide in an environment with a known C-weighted sound level (Berger, 2003). Octave band noise reduction data is collected per REAT methodology (IL values). The NRR is calculated using the pink noise spectrum (equal energy in each octave band); by subtracting the overall protected A-weighted sound level from the overall C-weighted ambient sound level. A-weighting is an approximation of equal loudness perception characteristics of human hearing for pure tones relative to a reference of $40 \mathrm{~dB}$ SPL at $1000 \mathrm{~Hz}$. C-weighting is the same approximation at $100 \mathrm{~dB}$ SPL at $1000 \mathrm{~Hz}$. It has been concluded that empirically derived measures using A-weighting give a better estimation of the threat to hearing than do any other weighting system (Earshen, 2003). An additional subtraction of a $3 \mathrm{~dB}$ spectral safety factor takes into account the use of pink noise instead of the actual noise spectrum. Finally, a two standard deviation adjustment factor is incorporated to account for variability and provide a value that would theoretically protect $98 \%$ of the population. For a summary of the NRR method, see the step-by-step sample calculations in Table A1, Appendix A.

Many studies have demonstrated that NRR attenuation values provided on protector packaging over-estimate the actual protection received by workers (Casali and Park, 1991; Berger et al., 1996; Giardino and Durkt, 1996, Neitzel et al., 2006). The need to evaluate actual HPD attenuation in the workplace provided the motivation for a controlled comparison of the REAT and MIRE methods to provide validation for the latter. Casali et al. (1995) compared data from several methods, including MIRE/IL and MIRE/NR to the $1 / 3$ octave band REAT method as outlined by ANSI (ANSI, 1974). NRR values were calculated for each method for a further comparison to the $1 / 3$ octave band REAT. The study found that physical methods, particularly the MIRE/NR, accurately estimated workplace protection. MIRE methods make field comparisons, especially real-time, on-the-job evaluations, feasible.

Giardino and Durkt (1996) summarized a series a studies conducted by the Mine Safety and Health Administration to measure on-the-job effectiveness of muff-type hearing protectors. Attenuation was measured using the MIRE method for selected workers at various mine sites. Subjects were instructed to don their HPD in the usual fashion after instrumentation was installed to record inside and outside noise spectra simultaneously. The researchers used estimated TFOE values to convert physical NR data to estimates of IL. For the purpose of validating the MIRE data, REAT measurements were conducted in a laboratory setting. As with results discussed previously, other than for lower frequencies $(<250 \mathrm{~Hz})$ the two methods produced results which compared favorably (discrepancies were $\leq 2.5 \mathrm{~dB}$ ) with negligible bias. Beyond verifying MIRE as an acceptable method for measuring HPD attenuation, the study concluded that for most HPD models and frequencies, the field-measured attenuation values were less than the 
advertised NRRs. This was especially true for operators of machines powered by internal combustion engines due, in part, to the low frequency of the noise produced and the tendency for REAT to overestimate attenuation at lower frequencies due to physiological noise masking (Giardino and Durkt, 1996).

Objective methods, such as MIRE, allow for the measurement of HPD performance at sound pressure levels well above threshold, an important distinction when testing in a field environment or in laboratory conditions simulating the field environment. However, there are two disadvantages to measuring IL using MIRE. First, measurements must be taken with and without the HPD (not simultaneous) which means the signal must be controlled as with the REAT method. This is time-consuming and not practical in the workplace where the ambient noise spectrum is likely to be erratic. Second, one of the required readings is with the unprotected ear, which limits the range of SPLs that can be tested. Taking simultaneous readings with HPD donned, inside and outside the protector, to determine NR is therefore a more feasible option allowing for greater flexibility.

Beyond the fact that the EPA NRR is determined from REAT-derived noise reduction data, there are other issues with the NRR procedure which may contribute to its overestimation of real world attenuations. First, the NRR is always computed using the pink noise spectrum. Since high frequency noise is easier to attenuate, use of pink noise exaggerates the reduction that will be obtained when low frequency noise dominates. Many industrial noise environments are low frequency dominant. Furthermore, the NRR method subtracts A-weighted protected values from $\mathrm{C}$-weighted unprotected pink noise, as opposed to subtracting from an A-weighted ambient noise spectrum. Because Cweighting factors are of generally lesser magnitude than A-weighting factors, especially at lower frequencies, this results in a higher overall unprotected sound level, which in turn leads to a higher NRR. To account for these two inconsistencies, the final NRR is further reduced by a $3 \mathrm{~dB}$ spectral safety factor (Berger, 2003).

\section{The Octave Band Method}

The Octave Band Method is considered the most accurate computational procedure for determining actual protected exposures (Berger, 2003). Two characteristics make this method more valid than the NRR procedure. First, the A-weighted protected noise level is subtracted from the A-weighted environmental noise. Second, all A-weighted values are calculated from the actual noise spectrum. The accuracy of this method depends on the reliability of the noise reduction data and the octave band noise measurements. Similar to the NRR method, the Octave Band method utilizes a 2-standard deviation correction factor to obtain an $\mathrm{OB}$ value that includes $98 \%$ of the sampled population $\left(\mathrm{OB}_{98}\right)$. For a summary of the OB method calculation, see Table A2, Appendix A. The OB Method and the NRR Method are contrasted further in this study for analyzing the MSA Sordin Supreme Pro headset and, for comparison, a standard industry earmuff, the Peltor Twin Cup H10A.

\section{Frequency Distribution and Computed Overall Attenuation}

One important distinction to make with any noise reduction rating is the relationship

between individual octave band noise reduction values and overall attenuation. Noise 
reduction values in each octave band are determined by subtracting the protected SPL from the unprotected SPL in that band. As a result, this is independent of the actual ambient noise level. If at $125 \mathrm{hz}$ one measures $10 \mathrm{~dB}$ of noise reduction at $80 \mathrm{~dB}$ ambient levels, then the noise reduction at an ambient level of $110 \mathrm{~dB}$ will still be $10 \mathrm{~dB}$. However, the overall noise reduction is highly dependent on the noise spectrum since it is the logarithmic sum of all octave band frequencies measured outside the HPD minus the logarithmic sum of all the octave band frequencies measured inside the HPD:

$$
S P L(d B)=10 \log \left[\sum_{i=1}^{N} 10^{\frac{S P L_{i}}{10}}\right]
$$

where: SPL is the total sound level

$\mathrm{SPL}_{\mathrm{i}}$ is each octave band SPL

$$
S P L_{\text {Overall }}=S P L_{\text {unprotected }}-S P L_{\text {portected }}
$$

where: $\mathrm{SPL}_{\text {overall }}$ is the $\mathrm{OB}$ or $\mathrm{NRR}$ noise reduction, $\mathrm{dB}$

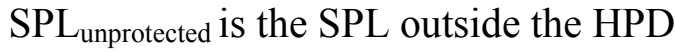

SPL $_{\text {protected }}$ is the SPL inside the HPD

Figure 1. Peltor Twin Cup H10A Manufacturer Noise Reduction Data

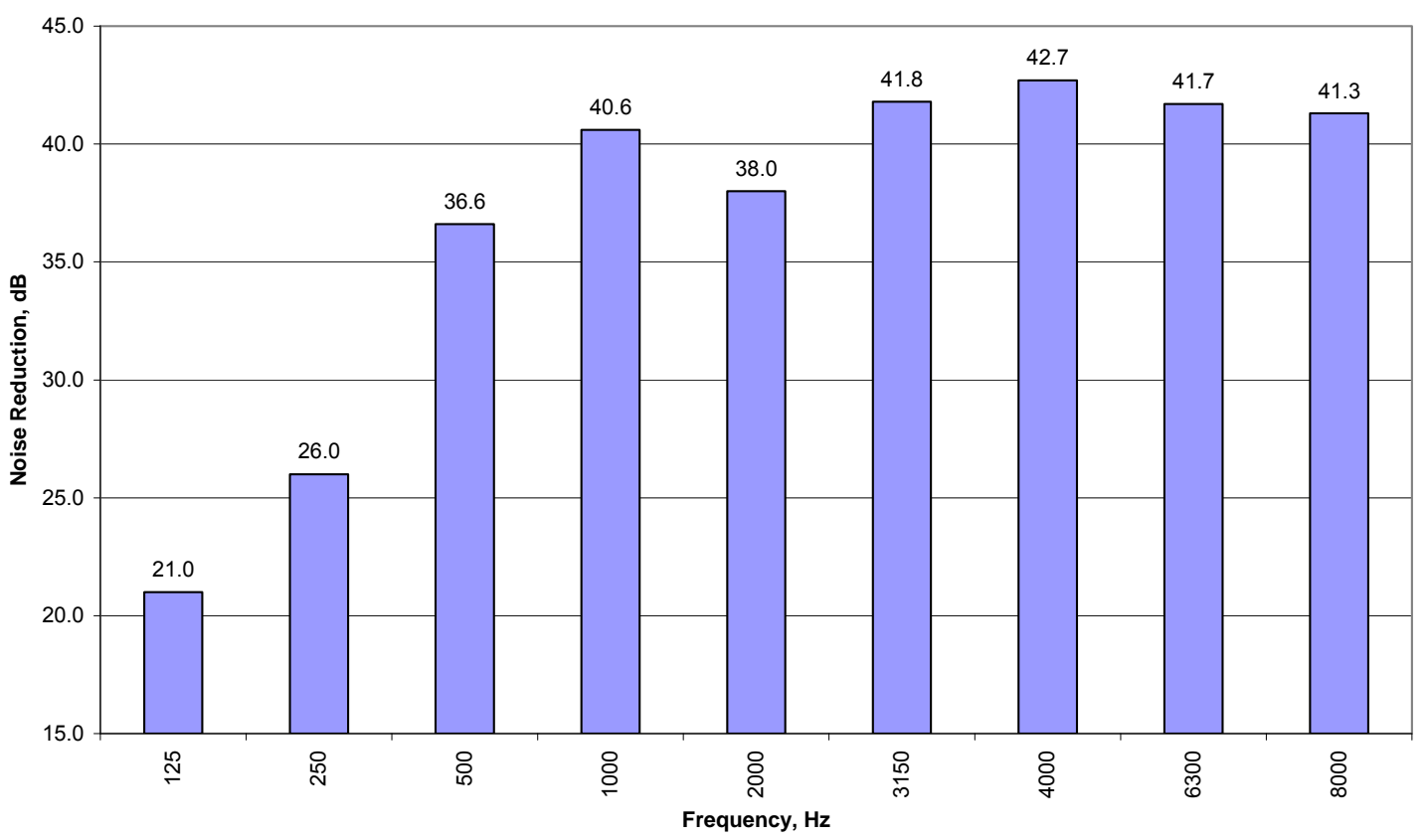


The overall noise reduction dependence on the noise spectrum is demonstrated here using the manufacturer's data for the Peltor Twin Cup H10A earmuff to calculate the $\mathrm{OB}_{98}$ attenuation in two different noise spectrums. The OB method must be used since by definition the NRR is only calculated using the pink noise spectrum. Figure 1 shows the Peltor H10A noise reduction values for frequency bands from 125 to $8000 \mathrm{~Hz}$ from manufacturer data. $\mathrm{OB}_{98}$ attenuation will be calculated for two different noise spectrums to illustrate the effect of the noise spectrum on overall attenuation. One spectrum is representative of low frequency dominant noise; the other is representative of high frequency dominant noise. The two spectra are presented in Figure 2.

Figure 2. Low and High Frequency Dominant Noise Fields

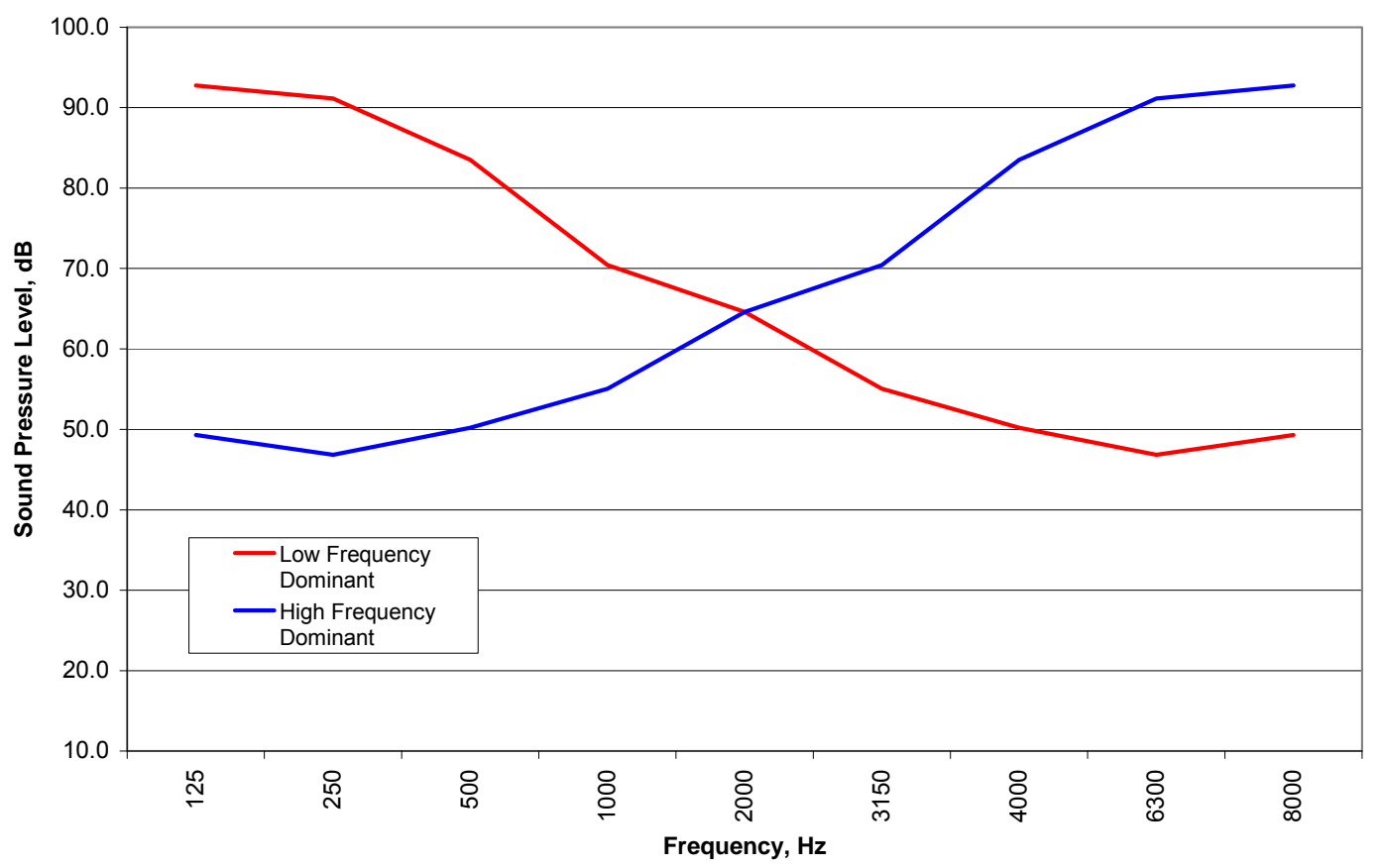

Table 1. $\mathbf{O B}_{98}$ Calculation for Low Frequency Dominant Noise Spectrum

\begin{tabular}{|l|l|c|c|c|c|c|c|c|c|c|c|c|}
\hline Line & Frequency, $\mathrm{Hz}$ & 125 & 250 & 500 & 1000 & 2000 & 3150 & 4000 & 6300 & 8000 & SPL & OB $_{98} * * *$ \\
\hline \hline 1 & Ambient Noise, dB & 92.8 & 91.1 & 83.5 & 70.4 & 64.6 & 55.0 & 50.2 & 46.8 & 49.3 & & \\
2 & $\begin{array}{l}\text { A-Weighting Corrections, } \\
\text { dB }\end{array}$ & -16.1 & -8.6 & -3.2 & 0.0 & 1.2 & 1.2 & 1.0 & -0.1 & -1.1 & & \\
\hline & $\begin{array}{l}\text { A-Weighted Unprotected } \\
\text { Noise, dBA }\end{array}$ & 76.7 & 82.5 & 80.3 & 70.4 & 65.8 & 56.2 & 51.2 & 46.7 & 48.2 & 85.4 & \\
\hline 4 & Avg Attenuation, dB & 21.0 & 26.0 & 36.6 & 40.6 & 38.0 & 41.8 & 42.7 & 41.7 & 41.3 & \\
\hline 5 & Std Dev & 1.9 & 2.3 & 2.3 & 2.4 & 2.5 & 2.7 & 1.8 & 2.1 & 2.5 & \\
\hline 6 & Std Dev x 2 & 3.8 & 4.6 & 4.6 & 4.8 & 5.0 & 5.4 & 3.6 & 4.2 & 5.0 & \\
\hline 7 & $\begin{array}{l}\text { Average Protection Value } \\
\text { (APV) }\end{array}$ & 17.2 & 21.4 & 32.0 & 35.8 & 33.0 & 36.4 & 39.1 & 37.5 & 36.3 & & \\
\hline 8 & $\begin{array}{l}\text { Protected Ear A-Weighted } \\
\text { SPL** }\end{array}$ & 59.5 & 61.1 & 48.3 & 34.6 & 32.8 & 19.8 & 12.1 & 9.2 & 11.9 & 63.5 & 21.9 \\
\hline
\end{tabular}

$*$ APV $=$ Avg. Attenuation -2 Std Dev $=$ Line 4 - Line 6

** Protected Ear A-Weighted SPL = A-Weighted Pink Noise, dBA - APV = Line 3 - Line 7

*** OB98 $=$ Unprotected A-Weighted Total SPL - Protected A-Weighted Total SPL 
Tables 1 and 2 present the step-by-step calculation of the $\mathrm{OB}_{98}$ for the low frequency dominant spectrum and the high frequency spectrum respectively. Note that the $\mathrm{OB}_{98}$ value for the low frequency spectrum is $21.9 \mathrm{dBA}, 15 \mathrm{dBA}$ lower than that achieved for the high frequency noise spectrum. The significant difference in overall attenuation is a function of the noise spectrum and the spread of noise reduction values over each frequency band characteristic of the HPD.

Table 2. $\mathbf{O B}_{98}$ Calculation for High Frequency Dominant Noise Spectrum

\begin{tabular}{|l|l|c|c|c|c|c|c|c|c|c|c|c|}
\hline Line & Frequency, Hz & 125 & 250 & 500 & 1000 & 2000 & 3150 & 4000 & 6300 & 8000 & SPL & OB $_{98}^{* * *}$ \\
\hline \hline 1 & Ambient Noise, dB & 49.3 & 46.8 & 50.2 & 55.0 & 64.6 & 70.4 & 83.5 & 91.1 & 92.8 & & \\
\hline 2 & A-Weighting Corrections, dB & -16.1 & -8.6 & -3.2 & 0.0 & 1.2 & 1.2 & 1.0 & -0.1 & -1.1 & \\
\hline & $\begin{array}{l}\text { A-Weighted Unprotected Noise, } \\
\text { dBA }\end{array}$ & 33.2 & 38.2 & 47.0 & 55.0 & 65.8 & 71.6 & 84.5 & 91.0 & 91.7 & 94.8 \\
\hline 4 & Avg Attenuation, dB & 21.0 & 26.0 & 36.6 & 40.6 & 38.0 & 41.8 & 42.7 & 41.7 & 41.3 & \\
\hline 5 & Std Dev & 1.9 & 2.3 & 2.3 & 2.4 & 2.5 & 2.7 & 1.8 & 2.1 & 2.5 & \\
\hline 6 & Std Dev x 2 & 3.8 & 4.6 & 4.6 & 4.8 & 5.0 & 5.4 & 3.6 & 4.2 & 5.0 & \\
\hline 7 & $\begin{array}{l}\text { Average Protection Value } \\
\text { (APV)* }\end{array}$ & 17.2 & 21.4 & 32.0 & 35.8 & 33.0 & 36.4 & 39.1 & 37.5 & 36.3 & & \\
\hline 8 & $\begin{array}{l}\text { Protected Ear A-Weighted } \\
\text { SPL** }\end{array}$ & 16.0 & 16.8 & 15.0 & 19.2 & 32.8 & 35.2 & 45.4 & 53.5 & 55.4 & 57.9 & 37.0 \\
\hline
\end{tabular}

* APV $=$ Avg. Attenuation -2 Std Dev $=$ Line 4 - Line 6

** Protected Ear A-Weighted SPL = A-Weighted Pink Noise, dBA - APV = Line 3 - Line 7

***OB98 = Unprotected A-Weighted Total SPL - Protected A-Weighted Total SPL

\section{Variability and Clamp Force}

What factors account for the variability among subjects? HPD noise reduction capacity obviously goes beyond the physical attenuation ability of the muff material. Earmuff clamp force is one important factor that may play a role in noise reduction capability. Clamp force is a function of both the ear muff construction and the anthropometry of the human head.

Researchers have found that while clamp force is not necessarily indicative of subjective comfort, it may be important for evaluating attenuation (Berger and Mitchell, 1989). Studies have shown that earmuff clamp force correlates positively with attenuation (Flugrath and Wolfe, 1971; Casali and Grenell, 1990). Clamp force, as a function of HPD manufacture and human anthropometric variability, may be the primary contributing factor to the noise reduction variability among workers wearing the same hearing protectors. Comfort and wearing time may also contribute to this variability in a real world setting but these factors were not analyzed in this study.

\section{Communication and Its Importance to Worker use of HPDs}

One of the key factors which has historically contributed to worker resistance to wearing hearing protection is the problem of communication. Because HPDs affect all noise entering the ear, including alarm signals and speech as well as unwanted noise, they can potentially reduce the ability to hear alarms or understand what a co-worker might be 
saying. Researchers have found it expedient to study not only the attenuating characteristics of hearing protectors, but also to test the effects of hearing protectors on worker's ability to detect important warning signals or communicate verbally with coworkers (Howell and Martin, 1975).

Howell and Martin (1975) set out to determine why many workers who regularly wear hearing protection continue to indicate that HPDs make normal communications difficult, despite the fact that previous research had suggested that hearing protectors did not degrade verbal communication at levels above 85 dBA (Kryter, 1946; Pollack, 1957). Beyond investigating the effects of HPDs on listener's ability to understand speech, they also studied how voice levels of talkers were affected while wearing HPDs. They hypothesized that while intelligibility may not be negatively affected by wearing HPDs in noise, perhaps there was a change in speech patterns for talkers wearing HPDs. They found that at levels greater than $85 \mathrm{dBA}$, HPDs did not degrade speech intelligibility (as in the Kryter and Pollack studies, the Howell and Martin study was conducted by introducing the signal into the space electronically along with the background noise, not from a person in the space wearing hearing protection). However, they also discovered that talkers wearing hearing protection will reduce their voice level to the extent that the intelligibility for the listener is degraded. The researchers concluded that talkers instinctively adjust their voice to sufficient levels to overcome background noise. When background noise is attenuated by hearing protection, the voice level is lowered since less projection is required to overcome the attenuated noise level (Howell and Martin, 1975).

In the Howell and Martin study, intelligibility was indicated by the percentage of correct responses to word lists which were presented at different speech levels in differing background noise environments. Other studies have investigated the intelligibility effects of HPDs using the Hearing in Noise Test (HINT). HINT was developed to measure the sentence Speech Reception Threshold (sSRT), which is the presentation level (sound pressure level) necessary for a listener to recognize spoken material correctly $50 \%$ of the time in background noise (Nilsson, et al., 1994). SRT is a direct measure of speech-tonoise $(\mathrm{S} / \mathrm{N})$ ratio and, as such, can only indirectly indicate the effect of hearing protectors on speech intelligibility. It can be inferred that the higher the $\mathrm{S} / \mathrm{N}$ ratio with a particular HPD, the more positive the effect that the HPD has on speech intelligibility.

\section{HPDs with Communication Features}

Because of the communication difficulties often encountered by workers in especially noisy environments, some HPDs have been modified to include communication features. Ear phones can be integrated into ear-muffs (and even ear plugs) providing the listener with an enhanced verbal signal. These communications systems can be wireless or hard wired systems and can be designed for one and two-way communications (Berger, 2003; Casali and Berger, 1996). Several factors determine the intelligibility of intercom speech. Ambient noise at the speaker's microphone can lessen intelligibility by degrading input signal quality. A second factor is the ambient noise at the ear. The speech-to-noise ratio at the earphone seems to be the single greatest limiting factor for intercom speech intelligibility. Therefore, for an objective measure of intercom speech intelligibility, the most important characteristics to consider would be input signal 
transmission and the attenuation characteristics of the HPD. This data provides the speech-to-noise ratio at the ear within the communication headset.

The attenuation characteristics of the headset hearing protector can be determined employing any one of the methods discussed above. Speech transmission quality requires an understanding of the physics behind the conversion of speech to an electronic signal at the microphone, frequency filtering and amplification, and then subsequent conversion of the signal to electronic speech at the earphone. A physical method to measure intercom speech-transmission quality was developed by Steeneken and Houtgast in 1980. The underlying concept of their approach is based on the Modulation Transfer Function (MTF) of a transmission channel and was adapted to account for the nonlinear distortions (peak clipping) as well as for distortions in the time domain (reverberation, echoes and automatic gain control). The resulting index is the Speech Transmission Index (STI), which yields an intelligibility score between 0 and 1 and was correlated with subjective intelligibility scores obtained from known psychophysical measures of intelligibility (Steeneken and Houtgast, 1980). This objective measure of speech transmission quality can provide insight into speech intelligibility for communications based, hearing protection systems.

For this study, attenuation data was collected using MIRE/NR methodology. Intelligibility was tested using techniques developed by Howell and Martin (1975) and Nilsson et al. (1994). An objective measure of speech transmission quality will not be undertaken for this project. The intelligibility tests using human subjects speaking over real noise will be sufficient to determine the communication enhancement of the MSA Sordin headset. 


\section{Apparatus}

1. The instrument used to record the 47 foot MLB noise in the field was a Nagra ARES-PII+ (Figure 3). The Nagra ARESPII+ is a high quality, digital, solid-state audio recorder that provides professional sound quality, recording the sound field as a .wav file format. A Larson-Davis SLM, Model 831, was used at the same time to measure the ambient sound pressure level and to perform a $1 / 3$ octave band frequency analysis. This field measured noise spectrum was used to confirm the correction of the noise spectrum measured in the reverberation chamber (see Figures 12 and 13 below). Noise was recorded during a 30-min cruise along the Ocean City, MD shoreline onboard a CG Station Ocean City, MD 47 foot MLB. The majority of the data was recorded at cruising speed (1900 rpm).

2. Data was collected in a specially built sound chamber (see Figure 4) designed to maximize reverberation and thus create a nearly diffuse sound field. Data showed that the chamber was not perfectly reflective and did in fact absorb some higher frequency sound (see Results and Discussion). The reverberation chamber measures 9'1" x 11'3" x 7'5" with a total volume of 758 cubic feet. The walls and ceiling are 2" x 4" frame construction finished with dry wall over $3 / 8$ " plywood while the floor is hard wood. The inner surfaces were painted with 3 coats of "hard-shell" paint. The chamber is fitted with three Infinity Primus 160 speakers which provided the ambient noise field.

3. The sound system used to deliver sound to the reverberation chamber consisted of Behringer Europower Model EP1500 amplifiers (Figure 5). The amplifiers

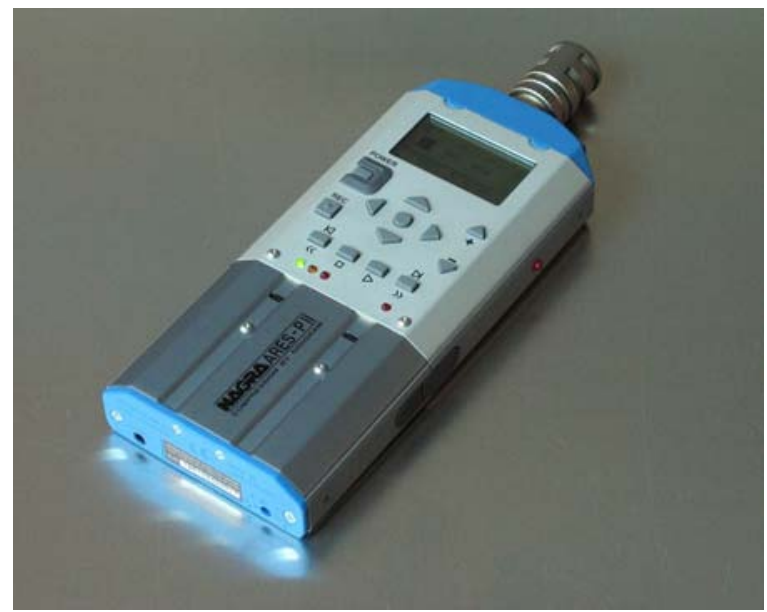

Figure 3. Nagra ARES-PII+

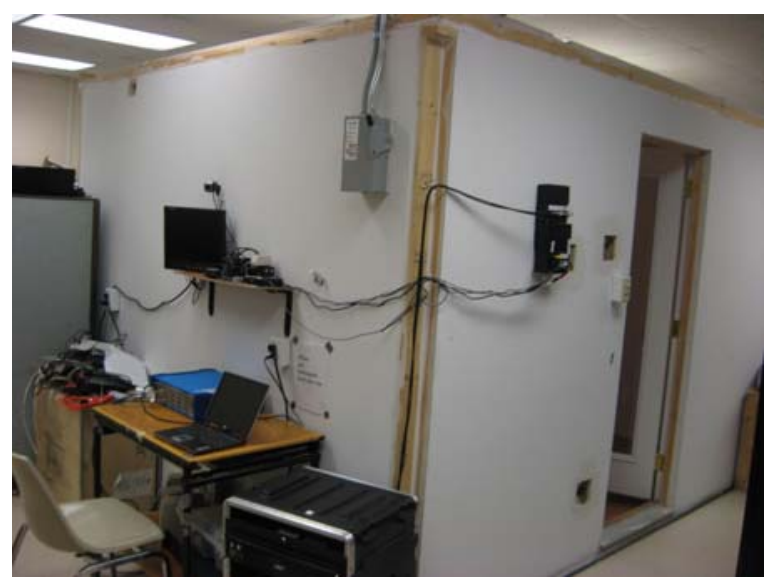

Figure 4. Reverberation Chamber

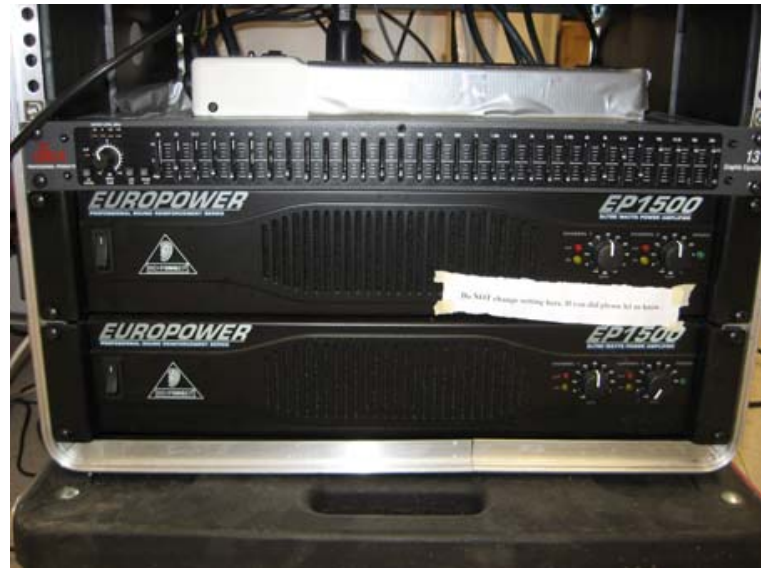

Figure 5. Europower Amplifiers 


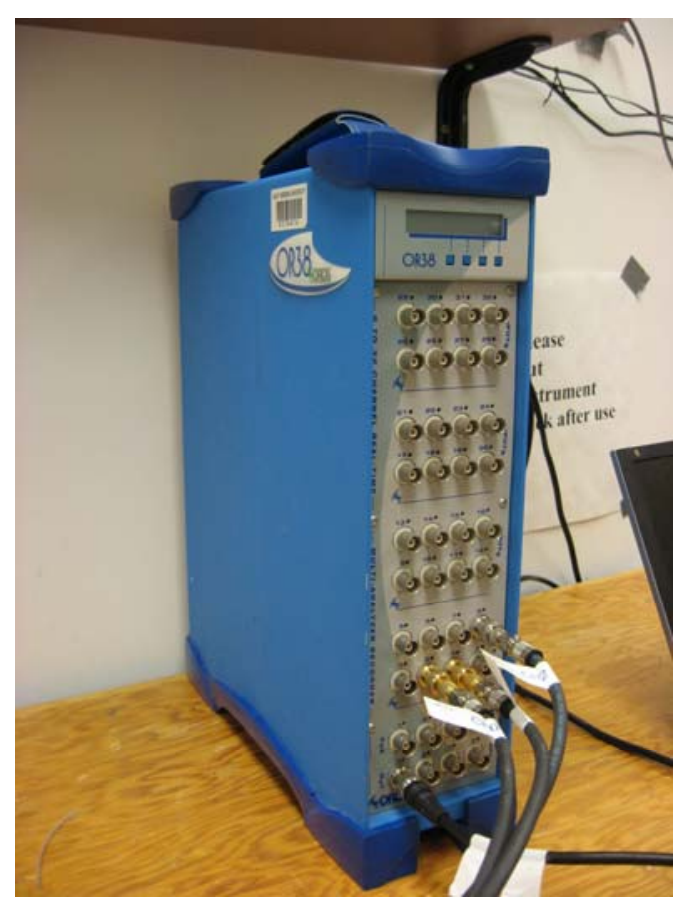

Figure 6. OROS OR38 Multi-analyzer

4. Clamp force was measured for each subject to demonstrate its relationship to noise reduction. Two anthropometric measurements required to determine clamp force are the median head width and the median head height (ANSI, 1997). These were measured using standard calipers and a micrometer. These measures were then applied to a clamp force meter which provided the clamp force in pounds. The clamp force indicator was designed and built for the WVU Industrial Hygiene Department by Dose Busters (Figure 8). received input from a Toshiba laptop computer. An OROS OR38 multianalyzer/recorder (Figure 6) was used to record noise data. The OROS OR38 multi-analysis capability provided the ability to simultaneously analyze different inputs in $1 / 3$ octave band frequencies. Three inputs were utilized; one microphone placed under the ear cup, one placed outside the ear cup (on the shoulder), and a third suspended near the center of the space, roughly 12 inches below the level of the ceiling. The OROS OR38 facilitated the use of the MIRE technique. The multi-analyzer was interfaced with the same Toshiba laptop for data analysis. The Dose Buster microphones used in conjunction with the OROS OR38 are shown in Figure 7.

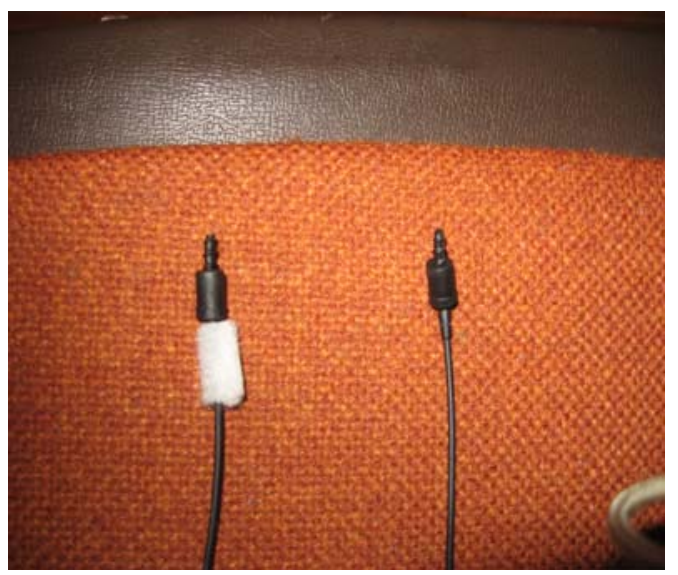

Figure 7. Microphones

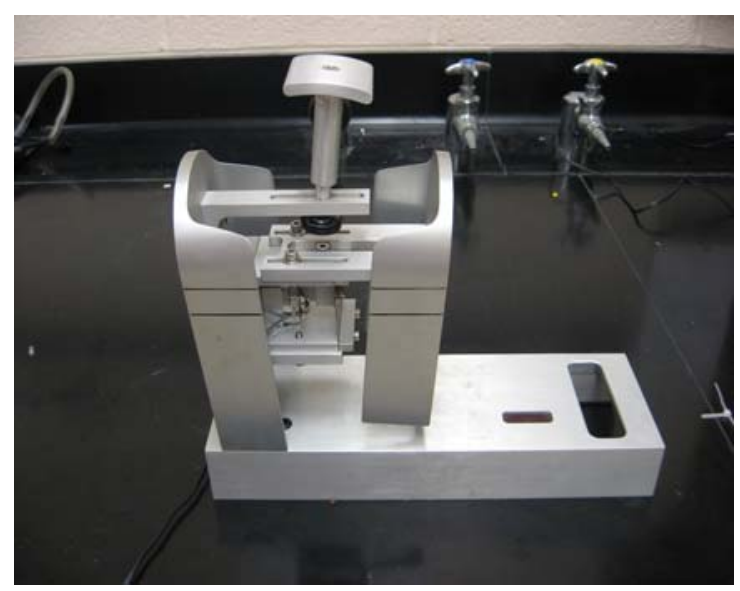

Figure 8. Clamp Force Indicator 


\section{Methods}

This study was broken down into two primary experiments: (1) the determination of speech intelligibility, and (2) the MIRE investigation to determine the noise attenuating characteristics of the communication headset. Both experiments were conducted using the noise spectrum recorded in the field on the USCG 47 footMLB to provide an accurate representation of the true operational environment.

\section{Subjects}

Eight subjects participated in the study. Noise reduction data was collected from all 8 subjects while only 4 participated in the intelligibility study. The subjects consisted of 5 males and 3 females, ranging in age from 23 to 47 years, with a mean of 31 yrs. The racial and cultural breakdown of the subjects was 6 White, 1 Hispanic, and 1 Asian. The goal was to study a subset of subjects which would reasonably reflect the diversity of a typical workplace with respect to sex and age. It must be noted that cultural diversity among subjects participating in the intelligibility study was limited due to the requirement for Standard English speakers. In a diverse workplace, such as the Coast Guard, regional and cultural dialectual differences will be present which will influence intelligibility. Intelligibility issues also exist to varying degrees with individuals from other countries who speak English as a second language. This diversity in spoken English will inevitably result in decreased intelligibility. This decreased intelligibility can be exacerbated by electronic communication, which must be considered when evaluating such a system. However, the goal of this study was to determine the effectiveness of electronic communications in noise, with the focus on the performance of the equipment. Thus, the effects of language were controlled to the greatest extent possible by selecting native, American English speakers. All subjects were briefed on the experimental methods and signed an informed consent form before participating.

\section{Speech Intelligibility Testing}

Human subjects taking part in the speech intelligibility portion of this study were audiometrically tested to ensure normal hearing (hearing level less than $20 \mathrm{~dB}$ from 0.25 to $8 \mathrm{kHz}$.) The speech intelligibility tests utilized sentences which were equated for naturalness, length, and intelligibility, and were phonetically matched and balanced (Nilsson, et al., 1994). The lists of sentences used is included in Appendix C. The sentences contain words natural and common to the English language, and therefore all subjects who participated in the speech intelligibility experiment were native speakers of standard American English. This ensured that intelligibility scores were not degraded by linguistic/idiomatic misinterpretation, but rather were a function of the capability of the communication system under study.

Speech intelligibility was determined by applying the HINT test, but in a slightly different manner than designed and conducted by Nilsson et al., (1994). Rather than determining the sentence speech reception threshold (requires adjusting the signal/noise ratio to reach the threshold of $50 \%$ intelligibility), the extent of speech intelligibility was scored directly at fixed background noise levels of 80, 90, and $100 \mathrm{dBA}$. Subjects were 
paired with one reading a list of sentences aloud while the other transcribed what he or she heard. When all sentences in the list had been read and recorded, the two subjects switched roles. Each test was conducted with a new, randomly selected list. The test was carried out with both talker and listener confined to the simulated, ambient noise environment of the reverberation chamber since ambient noise at the talker's microphone plays a role in the intelligibility of the modified and transmitted signal. Each recorded list was graded against the original. The test was conducted with the communication system activated (including headphone amplification) and with the system disconnected (including headphone amplification off) for comparison.

The orientation of the subjects during the intelligibility tests is presented in Figures 9 and 10. It was determined that subjects should face each other for the tests conducted with communications off since in the real world people speak facing each other. This decision was made with full understanding that this would bias the data in favor of increased intelligibility with communications off. This provided for a more conservative comparison since the expected result was a significant increase in intelligibility with communications. However, the subjects were instructed to look down and not at each other to control for visual intelligibility.

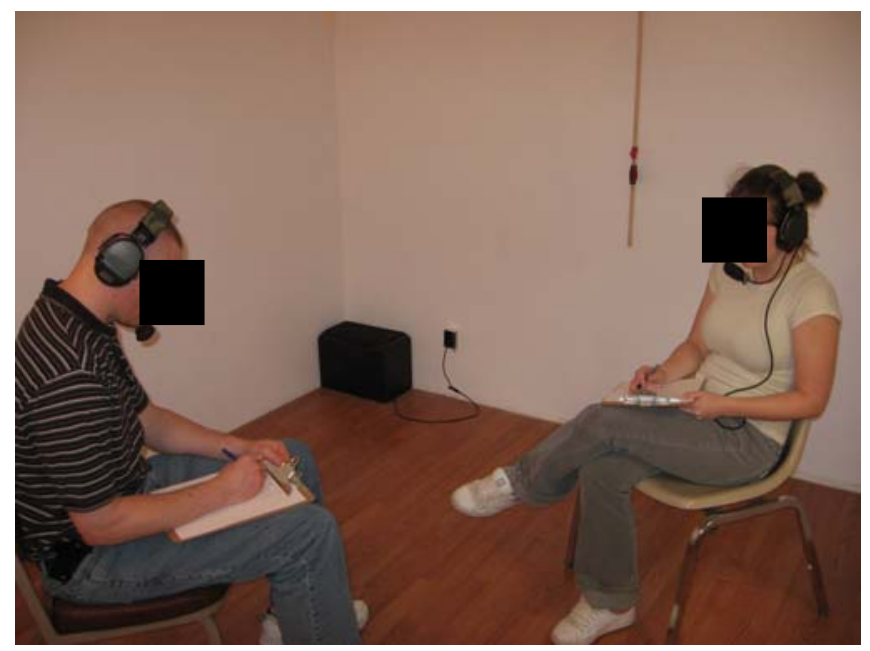

Figure 9. Speech Intelligibility - Communications Off

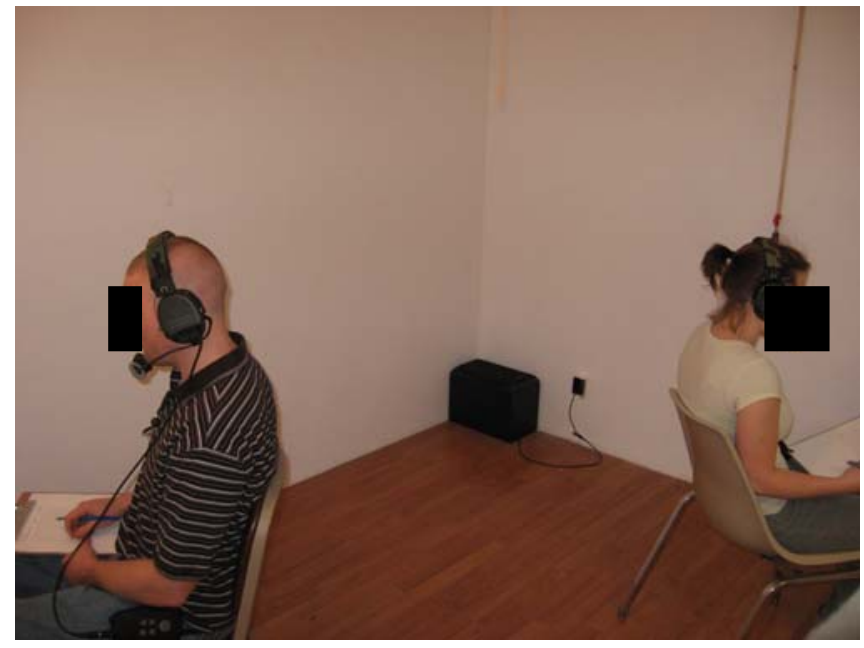

Figure 10. Speech Intelligibility - Communications On

\section{Noise Reduction Testing}

Noise data was collected using MIRE/NR methodology. Noise levels were recorded simultaneously inside and outside of the hearing protector. This was accomplished by inserting a small microphone inside the earmuff ( $\left.\mathrm{SPL}_{\text {ear }}\right)$ and by attaching another microphone outside the protector on the shoulder $\left(\mathrm{SPL}_{\text {shoulder }}\right)$. Data was collected without signal output from the headset headphone (wireless communication) in order to gauge the actual attenuation ability of the muff. The effects of headphone signal output from wireless communications on noise reduction were not examined in this study. 


\begin{tabular}{|l|l|c|c|c|c|c|c|c|c|c|c|}
\cline { 3 - 11 } Hearing Protector & 125 & 250 & 500 & 1000 & 2000 & 3150 & 4000 & 6300 & 8000 & NRR \\
\hline \multirow{2}{*}{$\begin{array}{l}\text { MSA Sordin } \\
\text { Supreme Pro }\end{array}$} & $\begin{array}{l}\text { Avg } \\
\text { Attenuation, dB }\end{array}$ & 11.1 & 16.5 & 23.1 & 25.0 & 29.5 & - & 35.5 & 38.3 & 38.7 & \multirow{2}{*}{18.0} \\
\cline { 2 - 13 } & Std Dev & 2.6 & 3.0 & 3.2 & 2.8 & 4.1 & - & 3.6 & 4.0 & 3.2 & \\
\hline \hline
\end{tabular}

Noise reduction data was also collected for a typical industry earmuff for comparison to the MSA Sordin headset. The earmuff selected was the Peltor Twin Cup H10A. Data collection and analysis methodology for the Peltor earmuff was identical to the MSA Sordin headset. Table 3 provides the manufacturer data for the two hearing protectors. MSA Sordin does not indicate whether their data is with the amplification feature off or on, nor do they allude to any difference between the two states. Manufacturer data listed for the MSA Sordin Supreme Pro is presumed to be with the amplification feature off based on the findings of this study.

Frequency specific noise reduction data was used to determine overall noise reduction values, such as NRR, OB, and linear values. Examples of these calculations are provided in Appendix A, Tables A1 for NRR and Table A2 for linear and OB calculations using the manufacturer provided data for the MSA Sordin Supreme Pro headset.

\section{Statistical Analysis}

Overall noise reduction values calculated from manufacturer and study data were compared to determine if the difference between means was significant. Confidence intervals were calculated for the difference between each set of means. The pooled variance for two means is calculated as follows:

$$
s_{p}=\sqrt{\frac{\left(n_{1}-1\right) s_{1}^{2}+\left(n_{2}-1\right) s_{2}^{2}}{n_{1}+n_{2}-2}}
$$

where: $s_{\mathrm{p}}$ is the pooled estimate of the population standard deviation

$\mathrm{n}_{1}$ is the sample size of sample 1

$\mathrm{n}_{2}$ is the sample size of sample 2

$\mathrm{s}_{1}$ is the standard deviation of sample 1

$\mathrm{s}_{2}$ is the standard deviation of sample 2

In this case the variance of the calculated manufacturer NR values was not known (manufacturer standard deviation data was at the noise reduction level for each frequency). At the frequency level, the manufacturer variance was routinely lower than the study variance. Therefore, assuming unknown but equal variance between the samples we can conservatively assume that the manufacturer NR values had the same 
variance as the study data. This conservative approach yielded pooled standard deviations which were the same as the $s_{1} / s_{2}$ values.

The Confidence Intervals (CI) were calculated with Equation 7:

$$
C I=\left(x_{1}-x_{2}\right) \pm t_{\alpha / 2} s_{p} \sqrt{\frac{1}{n_{1}}+\frac{1}{n_{2}}}
$$

where: $\mathrm{CI}$ is the confidence interval

$\mathrm{x}_{1}$ is the mean for sample 1

$\mathrm{x}_{2}$ is the mean for sample 2

$\mathrm{t}_{\alpha / 2}$ is the $\mathrm{t}$-value with $\mathrm{v}=\mathrm{n}_{1}+\mathrm{n}_{2}-2$ degrees of freedom

$\mathrm{s}_{\mathrm{p}}$ is the pooled estimate of the population standard deviation

$\mathrm{n}_{1}$ is the sample size of sample 1

$\mathrm{n}_{2}$ is the sample size of sample 2

An alpha of 0.05 was used to calculated both upper and lower confidence intervals. A Lower Confidence Limit (LCL) greater than zero indicates that there is only a $2.5 \%$ chance or less that the means could be equal.

Finally, performing a two sample pooled T-Test demonstrates the unlikelihood that the samples are equal. The test statistic, $\mathrm{t}$, was calculated from the following equation:

$$
t=\frac{\left(x_{1}-x_{2}\right)-d_{0}}{s_{p} \sqrt{1 / n_{1}+1 / n_{2}}}
$$

where: $\mathrm{t}$ is the test statistic for the two-sample pooled T-Test

$\mathrm{x}_{1}$ is the mean for sample 1

$\mathrm{x}_{2}$ is the mean for sample 2

$\mathrm{d}_{0}$ is the difference between the sample means to be tested

$\mathrm{s}_{\mathrm{p}}$ is the pooled estimate of the population standard deviation

$\mathrm{n}_{1}$ is the sample size of sample 1

$\mathrm{n}_{2}$ is the sample size of sample 2

The $t$ statistic can either be compared to a critical $t$ value based on the desired level of significance or the corresponding p-value can be compared. In this case, since the manufacturer means were higher than the study data, a one tailed test was performed at $\alpha$ $=0.025$.

The correlation between clamp force and noise reduction was tested using linear regression to determine the coefficient of determination $\left(\mathrm{r}^{2}\right)$ and by calculating the correlation coefficient. The coefficient of determination expresses the proportion of the total variation in the values of $\mathrm{Y}$ (noise reduction) that can be explained by a linear 
relationship with the values of $\mathrm{X}$ (clamp force). The correlation coefficient (r) was calculated using EQ 9:

$$
r=\frac{S_{x y}}{\sqrt{S_{x x} S_{y y}}}
$$

where: $r$ is the correlation coefficient

$$
\begin{aligned}
& \mathrm{S}_{\mathrm{xx}}=\sum\left(\mathrm{x}_{\mathrm{i}}-\mathrm{x}\right)^{2} \\
& \mathrm{~S}_{\mathrm{yy}}=\sum\left(\mathrm{y}_{\mathrm{i}}-\mathrm{y}\right)^{2} \\
& \mathrm{~S}_{\mathrm{xy}}=\sum\left(\mathrm{x}_{\mathrm{i}}-\mathrm{x}\right)\left(\mathrm{y}_{\mathrm{i}}-\mathrm{y}\right)
\end{aligned}
$$

The t-statistic to determine the strength of the linear relationship was calculated as follows:

$$
t=\frac{r \sqrt{n-2}}{\sqrt{1-r^{2}}}
$$

where: $t$ is the statistic to determine linear association with $n-2$ degrees of freedom $r$ is the correlation coefficient $\mathrm{n}$ is the number of samples 


\section{Results and Discussion}

Speech Intelligibility, Noise Reduction, and Clamp Force were the primary dependent variables derived from this study.

\section{Speech Intelligibility}

The objective of this test was to determine whether the MSA Sordin headset, as part of the BCCS (with transceiver) had no effect when deployed in noise or whether it improved verbal communications.

Figure 11. Speech Intelligibility Scores

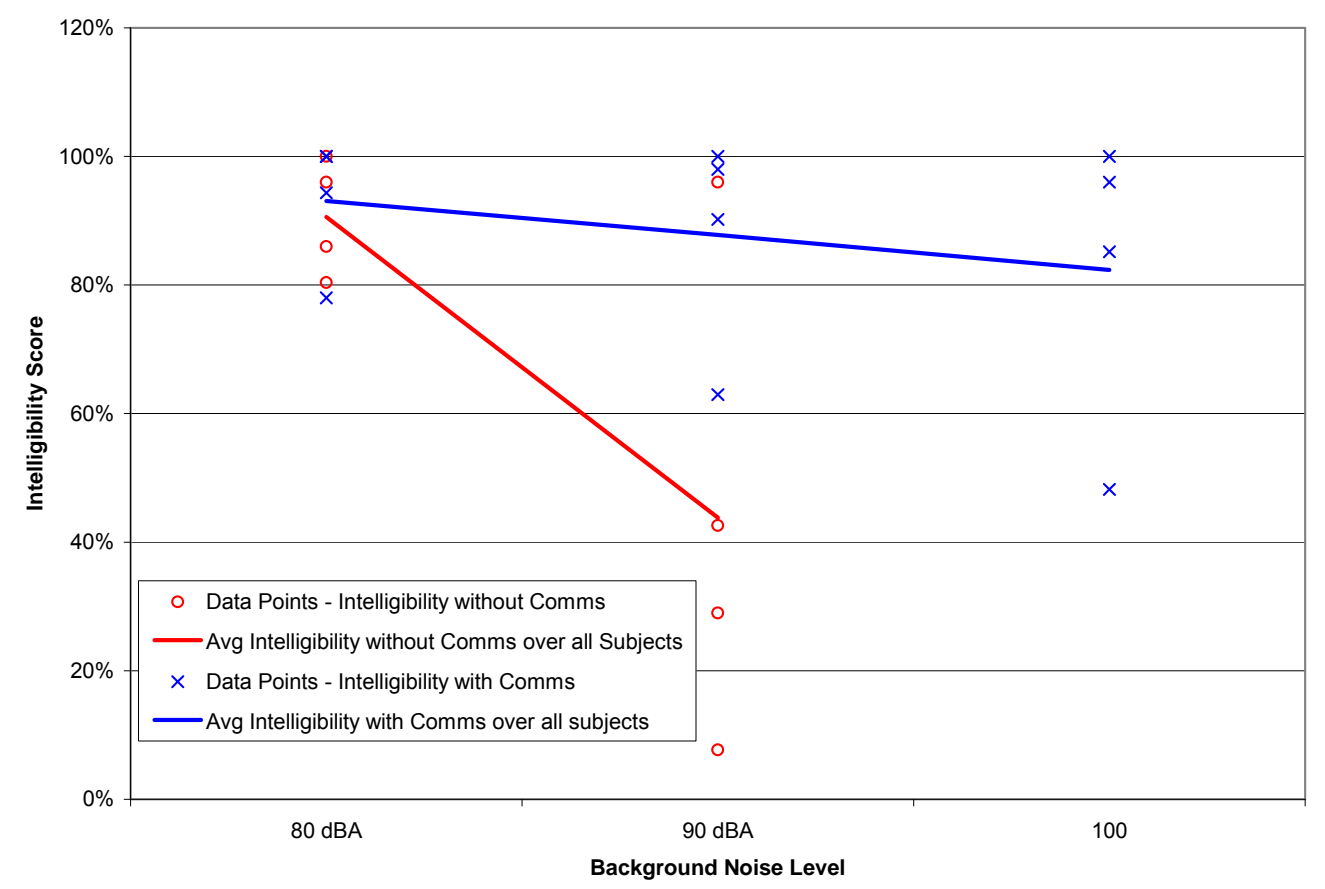

Intelligibility scores were calculated for each test and plotted in Figure 11. Due to the length and rigor of the intelligibility tests there were no replications. Figure 11 shows the dramatic advantage in intelligibility when the communications system was utilized compared to when the system was off.

The intelligibility data were so conclusive after testing four subjects that further testing was deemed unnecessary. It is clear from the data that the Telephonics communication system dramatically improves intelligibility. Subjects' performance was significantly enhanced at all three ambient noise levels with communications. For sound levels at 90 and $100 \mathrm{dBA}$, intelligibility was poor with communications turned off. None of the four subjects were tested at $100 \mathrm{dBA}$ without communications. Preliminary testing revealed that intelligibility was negligible at that level with the communications system off. 
Table 4. Speech Intelligibility Scores

\begin{tabular}{|c|c|c|c|c|c|c|c|c|c|c|}
\hline \multirow[b]{2}{*}{ Subject } & \multicolumn{5}{|c|}{ Without Comms } & \multicolumn{5}{|c|}{ With Comms } \\
\hline & 1 & 2 & 3 & 4 & AVG & 1 & 2 & 3 & 4 & AVG \\
\hline $80 \mathrm{dBA}$ & $86 \%$ & $100 \%$ & $80 \%$ & $96 \%$ & $91 \%$ & $78 \%$ & $100 \%$ & $94 \%$ & $100 \%$ & $93 \%$ \\
\hline $90 \mathrm{dBA}$ & $29 \%$ & $96 \%$ & $43 \%$ & $8 \%$ & $44 \%$ & $98 \%$ & $100 \%$ & $90 \%$ & $63 \%$ & $88 \%$ \\
\hline $100 \mathrm{dBA}^{*}$ & $\mathrm{n} / \mathrm{a}$ & $\mathrm{n} / \mathrm{a}$ & $\mathrm{n} / \mathrm{a}$ & $\mathrm{n} / \mathrm{a}$ & $\mathrm{n} / \mathrm{a}$ & $100 \%$ & $96 \%$ & $85 \%$ & $48 \%$ & $82 \%$ \\
\hline
\end{tabular}

The greatest variation was registered at $90 \mathrm{dBA}$ with the communications system off. Here intelligibility was hit or miss with the majority of subjects scoring well below $50 \%$ (see Table 4). However, a large range of variability was observed, running from $8 \%$ to $98 \%$ intelligibility. This range corresponded to the apparent strength and projection of the speaker's voice.

While intelligibility scores were uniformly high utilizing the electronic communications, there was some variability. Static, interference, and the dropping or chopping of words resulted in intelligibility scores below 90\% (see Table 4). These seem to be inherent problems with electronic communications systems. Due to these problems, it was determined that the procedure used to test the first group of subjects was not consistent with field practice. Due to the dropping and chopping of words, typically at the very beginning of a transmission, the operator will normally initiate the transmission by identifying the person being called and then themselves. This establishes the line of communication and eliminates the tendency of the system to drop the first word or two. Therefore the second group was instructed to start each sentence by stating the sentence number, i.e. "sentence 1..." and then the text. The intelligibility scores for the first group were lower, but the data was conservatively biased toward lower intelligibility. Therefore the data was accepted and included in the results. Despite the lower intelligibility scores by the first group with communications activated, overall intelligibility was still greatly improved by utilizing the electronic communications.

One experimental protocol issue discovered during this test was a phenomenon mentioned by several subjects. Occasionally during the reading of a sentence they would not catch a word but after hearing the rest of the sentence they guessed the word based on context clues. While this would skew intelligibility scores higher, it was present equally during communications on and off, therefore not affecting the disparity. Also this phenomenon occurs during normal communications and probably reflects the reality of the field environment.

\section{Noise Reduction}

\section{Reverberation Chamber Correction Factor}

In the course of collecting noise reduction data it was discovered that the reverberation chamber was not producing a perfect diffuse noise field. Some sound energy is absorbed, especially in the higher frequency ranges. For that reason, a correction factor for each 
Figure 12. Hypothetical Pink Noise vs. Actual Pink Noise

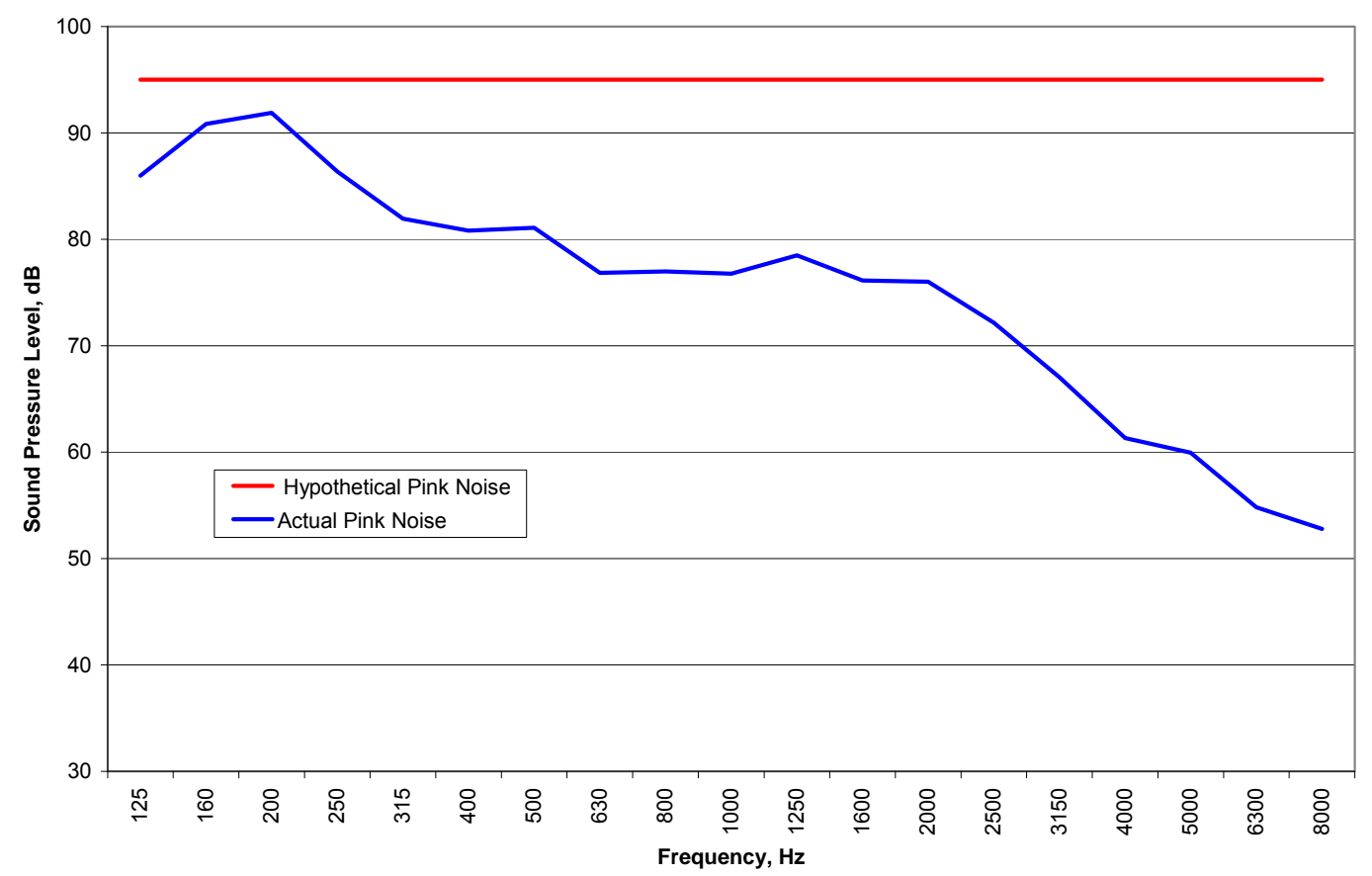

$1 / 3$ octave band frequency was developed from the discrepancy between measured SPL values for pink noise and the presumed actual values. Pink noise contains equal energy in each octave band creating a flat SPL curve when plotted. In Figure 12, a hypothetical pink noise spectrum is represented by the red line, a constant $95 \mathrm{~dB}$. The actual pink noise spectrum measured in the reverberation chamber is represented by the blue line. The difference between the two is the correction factor for the reverberation chamber. The actual SPL of the hypothetical pink noise does not matter. This correction factor must be applied to any other noise source measured in the chamber to provide the actual spectrum. This correction factor was applied to the 47 foot MLB noise spectrum, which was recorded in the field, and used to determine the noise reduction performance of the headsets in this experiment. Figure 13 shows the uncorrected MLB noise spectrum as recorded in the reverberation chamber versus the corrected spectrum. The actual field measured spectrum, measured by SLM at the same time the MLB noise spectrum was recorded, was overlaid to compare to the corrected spectrum (yellow line). This provides validation that the correction factors for the reverberation chamber are accurate.

The correct noise spectrum is not critical for determining noise reduction values for each octave band since the discrepancy cancels itself out. However, when determining the overall protection afforded by the HPD, regardless of the method utilized, the correct frequency spectrum is critical to the calculation of the overall noise reduction, as was demonstrated in Tables 1 and 2. The corrected MLB noise spectrum represented in Figure 13 is the spectrum used to determine the protection values calculated in the following sections. 
Figure 13. MLB Noise Spectrum Corrected vs. Field Measured Spectrum

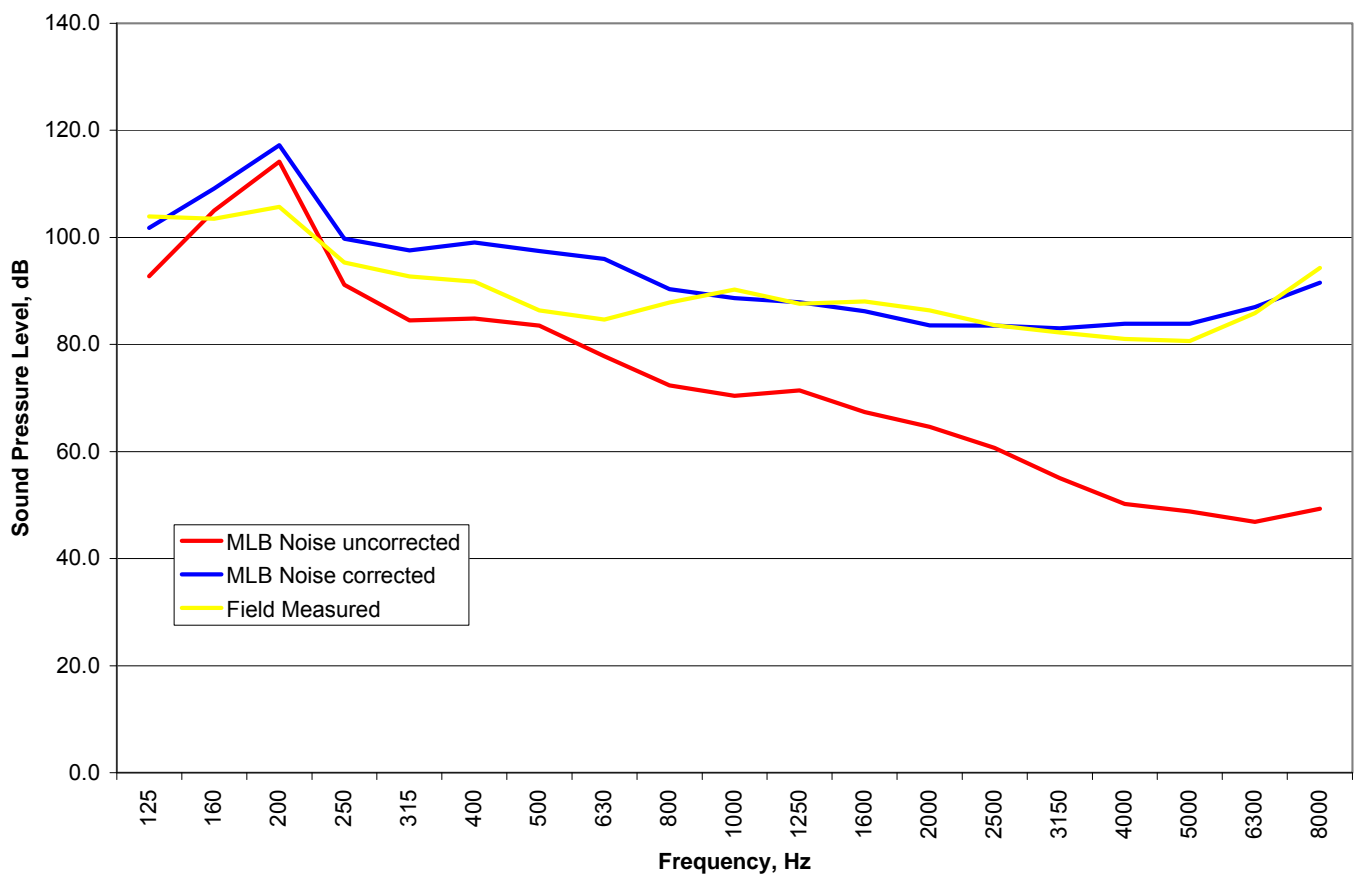

\section{Usability vs. Noise Reduction}

Before reviewing the results from the noise reduction experiment, one important issue must be discussed. Of the eight subjects that participated in the noise reduction experiment, one subject could not receive a sufficient seal with the MSA Sordin Supreme Pro headset due to a combination of factors. First, Subject 7 had a sharp jaw line which nearly formed a right angle with the neck just below the ear. This feature did not appear to be an abnormality or deformation of any kind, rather simply normal anthropometric variation. The sharp jaw line had no effect when measuring NR for the Peltor Twin Cup H10A earmuff. However, the jaw line allowed a visible gap with the MSA Sordin headset. The second factor was the width of the headset earmuff material. The Peltor earmuff appeared to completely form fit around the jaw, forming a good seal. The MSA Sordin headset had thinner earmuff depth (see Figure 14). The thinner earmuff material of the MSA Sordin headset visibly could not sufficiently seal Subject 7 at that jaw/neck interface. As a result, there was no effective noise

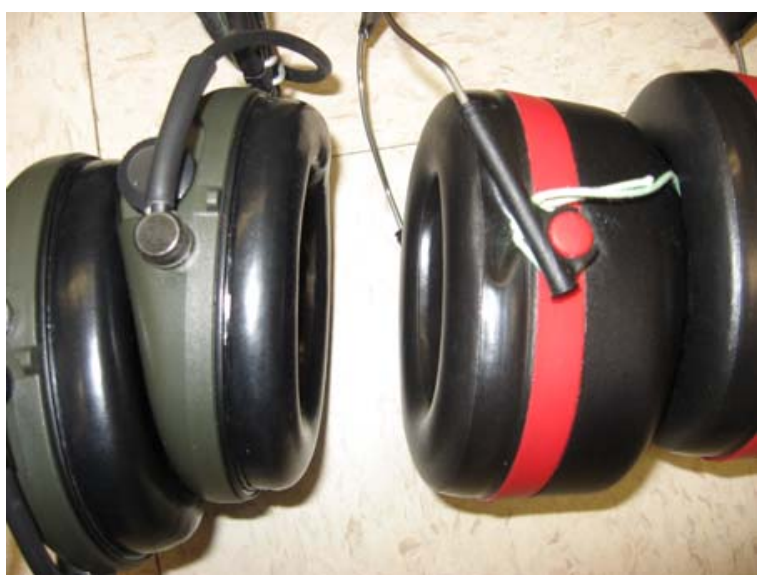

Figure 14. MSA Sordin on the left, Peltor on the right. Deeper Peltor cushion molds around anatomical features more thoroughly creating a better seal. 
amplification at every frequency range, even with the headset amplification feature turned off. The amplification suggests un-attenuated noise was entering the ear cup freely and reverberating.

Having one of eight users receive no protection was disturbing. However, subject fit was not a primary metric of this study. Therefore Subject 7's data was removed to evaluate the headset under ideal conditions. Subject 7's data is included for more comprehensive analysis in Appendix B.

\section{Amplification On vs Amplification Off}

The objective of this test was to determine whether the MSA Sordin headset amplification feature would alter the noise reduction characteristics of the headset.

The MSA Sordin headset provides the capability of amplifying noise in specific frequency ranges to enhance the wearer's ability to hear presumably wanted sound while reducing unwanted noise. The end result when this feature is energized is depicted in Figure 15. The scatter plot shows all noise reduction values collected with the amplification feature turned on versus noise reduction with the amplification feature turned off. It is readily apparent from Figure 15 that the amplification feature does have a profound effect on the noise reduction characteristics of the headset. From 400 to 8000 $\mathrm{Hz}$ the amplification feature lowers noise reduction at all frequencies. It is conclusive that when the amplification feature is activated it significantly changes the noise reduction capacity of the headset.

Figure 15. Noise Reduction: Amplification On vs. Amplification Off (Without Subject 7)

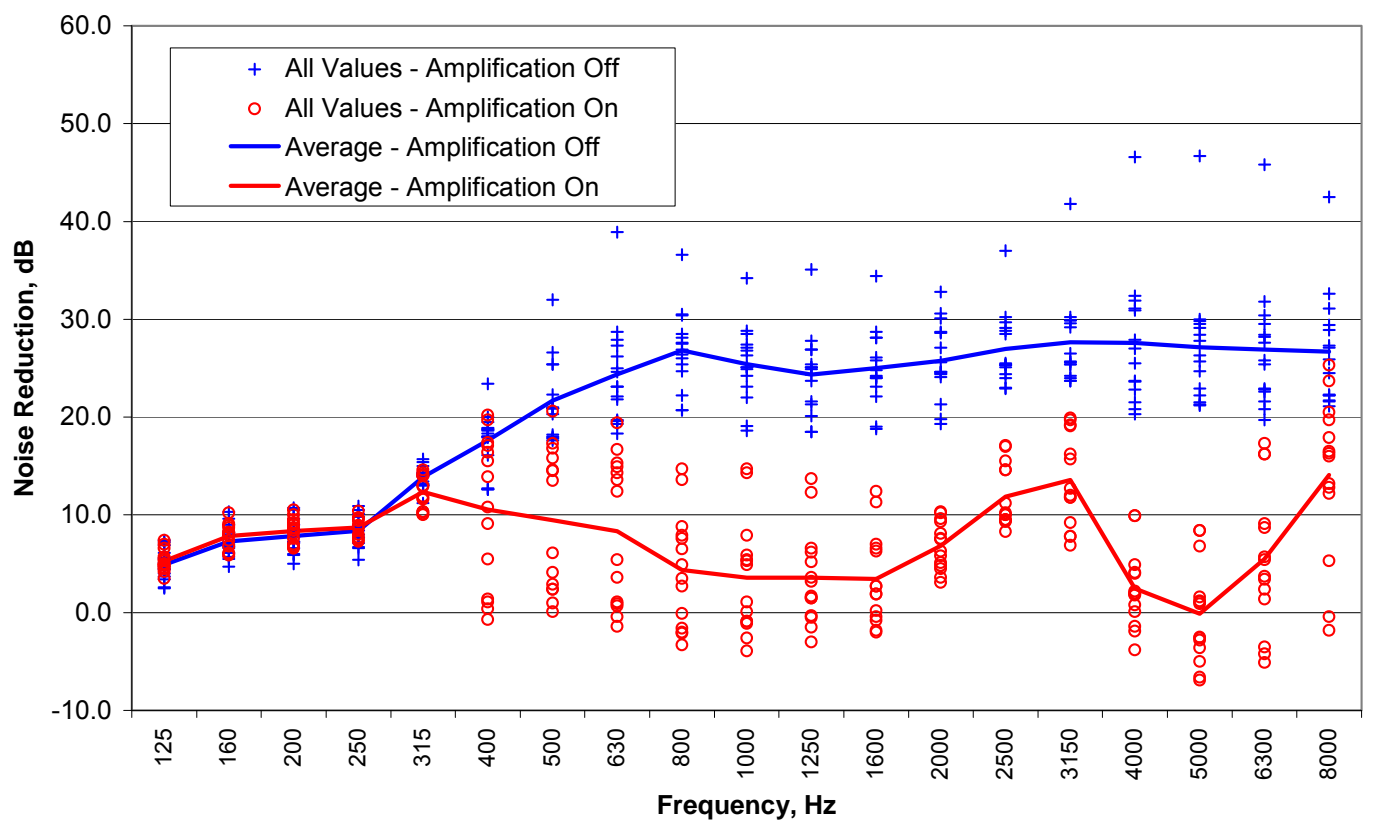




\section{Simulated Field Conditions (OB) vs. Manufacturer data (NRR)}

Using the noise reduction data collected, the goal was to calculate the overall Octave Band noise reduction and compare it to the manufacturer NRR to determine if the field simulated conditions would yield lower overall noise reduction.

The data provided by the manufacturer is with headset amplification off. Therefore Hypothesis 3 was tested comparing the manufacturer's data with the data collected in this study corresponding with amplification off. Figure 16 compares the manufacturer's data to the study data. The solid blue line represents the study mean. The confidence intervals for the manufacturer's data were calculated using an assumption of 20 samples which is the minimum number of samples required by the REAT method (ANSI, 1974). The study data overlaps considerably with the manufacturer confidence intervals from 500 to $2000 \mathrm{~Hz}$.

Figure 16. MSA Sordin Noise Reduction: Study Data vs. Manufacturer - Headset Amplification Off (Without Subject 7)

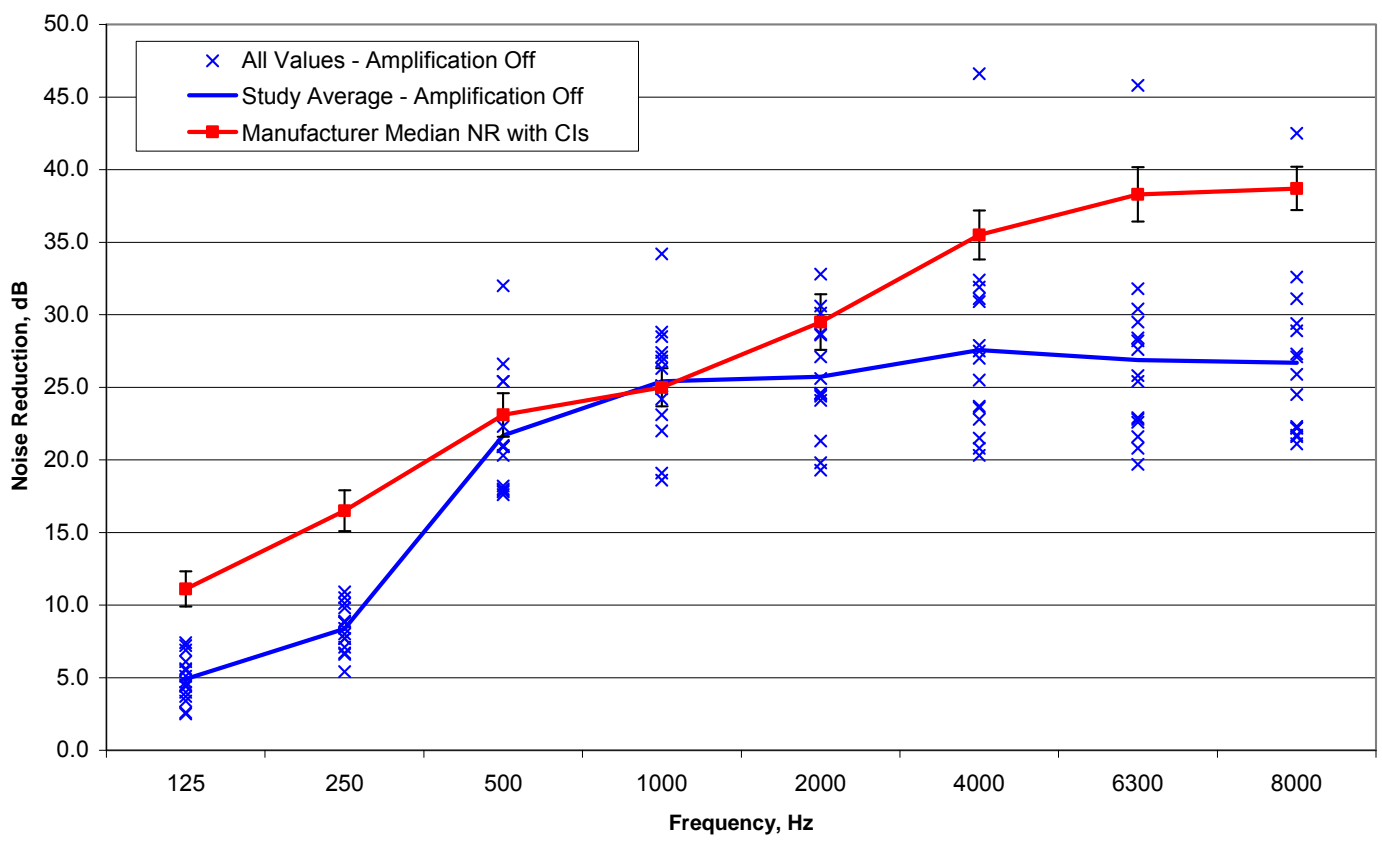


Figure 17. Peltor H10A Noise Reduction: Study Data vs. Manufacturer

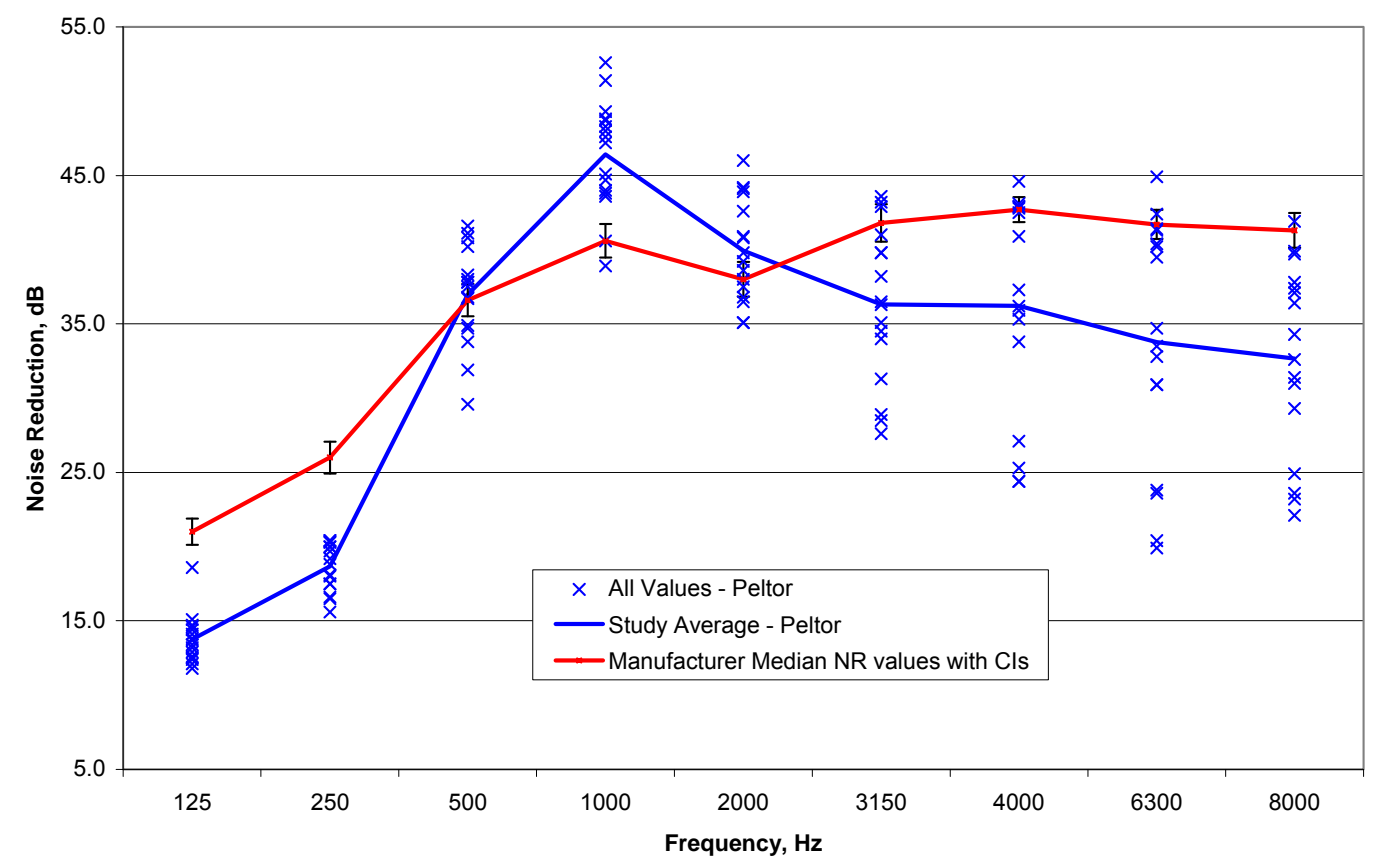

For comparison, the Peltor Twin Cup H10A study results are also plotted against manufacturer data $(n=20)$ in Figure 17. Similarly, overlap is observed in the $500 \mathrm{~Hz}$ to $2000 \mathrm{~Hz}$ range.

While this data demonstrates a clear trend toward lower noise reduction values, especially at lower and higher frequency ranges, an analysis of overall attenuation is required to definitively determine whether the field simulated condition results in lower attenuation than marketed NRR values. For the MSA Sordin headset, Table 5 shows the comparison of linear, C-Weighted and Octave Band mean (A-weighted) attenuation values calculated from the manufacturer's data and the study data for three different noise spectrums, pink noise, low frequency dominant noise (USCG 47 footMLB noise spectrum) and a mid range dominant noise spectrum (recreated from Howell and Martin, 1975). The masking noise fields used by Howell and Martin (1975) in their hearing in noise study concentrated the sound energy within the frequency range most likely to affect speech intelligibility.

The linear values are calculated strictly from noise reduction data; no weighting factors are incorporated. The $\mathrm{C}$-weighted values are similar to the linear values due to the fact that $\mathrm{C}$-weighting adjustments are relatively minor. The Octave Band Mean is the same as the A-weighted noise reduction, since the A-weighted protected noise level is subtracted from the unprotected A-weighted SPL (see calculations in Appendix A). The more substantial A-weighting factors account for the difference between the Octave Band mean and the other values. The NRR is only computed for the pink noise spectrum, and as discuss, it involves subtracting A-weighted protected values from $\mathrm{C}$-weighted ambient noise. The NRR here is the NRR mean without the 2 standard deviation adjustment. 
As depicted in Table 5, the NR values derived from study data are universally lower than the values calculated from the manufacturer data. This difference fluctuates however, depending on the noise spectrum. Using the mid range dominant spectrum we see the smallest difference between the study and manufacturer values. In this spectrum, the energy is concentrated in some of the same frequencies where overlap was observed in the frequency specific noise reduction plots (Figures 16 and 17). This results in the similarity between the study and manufacturer data. The low frequency spectrum produces the largest gap between the study and manufacturer values. Regardless of whether we observe the manufacturer data or the data collected in this study, we find that the OB method calculated using the 47 foot MLB low frequency noise spectrum yields lower overall noise reduction than the NRR method (19.4 vs. 24.4, dB manufacturer 11.2 vs. 19.4, dB study data).

Statistical comparisons reveal the significance of the disparity between the manufacturer and study data. The CI calculations indicate that all study derived overall noise reduction values are significantly less than the corresponding manufacturer values. In all cases, the $\mathrm{t}$-statistic falls outside the critical value, corresponding to $\mathrm{p}$-values much lower than 0.05 . This demonstrates that the manufacturer sample is significantly different from the data collected in this study. We can reject the hypothesis that the study data will yield similar values to the manufacturer data, and accept the alternative that the study results were significantly lower than the manufacturer's data.

Table 6 presents the same data for the Peltor H10A ear muff. Results for the Peltor earmuff comparison between study and manufacturer data were similar to the results of the MSA Sordin headset tests. 
Table 5. Statistical Analysis of Overall Attenuation Values - MSA Sordin Headset, Amplification Off (without Subject 7)

Pink Noise Spectrum

\begin{tabular}{|c|c|c|c|c|c|c|c|c|c|c|c|c|c|}
\hline \multicolumn{3}{|c|}{ Manufacturer } & \multicolumn{4}{|l|}{ Study } & \multicolumn{3}{|c|}{$\mathrm{CI}$ for $\mathrm{x}_{1}-\mathrm{x}_{2}$} & \multicolumn{4}{|c|}{ Two-Sample Pooled T-Test } \\
\hline NR Value & $\operatorname{NR}\left(\mathrm{x}_{1}\right)$ & $\mathrm{SD}\left(\mathrm{s}_{1}\right)^{*}$ & $\mathrm{NR}\left(\mathrm{x}_{2}\right)$ & $\mathrm{SD}\left(\mathrm{s}_{2}\right)$ & $s_{p}$ & $\mathrm{PE}$ & $\mathrm{LCL}$ & UCL & $\mathrm{LCL}>0$ & $\mathrm{t}_{\text {critical }}$ & $t_{\text {actual }}$ & $\mathrm{P}_{\text {value }}$ & Reject Null \\
\hline NR Linear & 18.6 & 1.4 & 13.2 & 1.4 & 1.4 & 5.5 & 4.5 & 6.4 & $\mathrm{Y}$ & 2.035 & 11.2 & $4.5 \mathrm{E}-13$ & Y \\
\hline NR C-Weighted & 18.1 & 1.4 & 12.9 & 1.4 & 1.4 & 5.2 & 4.2 & 6.2 & $\mathrm{Y}$ & 2.035 & 10.6 & $1.9 \mathrm{E}-12$ & $\mathrm{Y}$ \\
\hline NR A-Weighted & 26.8 & 1.5 & 21.6 & 1.5 & 1.5 & 5.2 & 4.2 & 6.2 & $\mathrm{Y}$ & 2.035 & 10.2 & $4.6 \mathrm{E}-12$ & $\mathrm{Y}$ \\
\hline NRR & 24.4 & 1.5 & 19.4 & 1.5 & 1.5 & 5.0 & 3.9 & 6.0 & $\mathrm{Y}$ & 2.035 & 9.7 & $2.0 \mathrm{E}-11$ & $Y$ \\
\hline
\end{tabular}

Low Frequency Noise Spectrum (47'MLB)

\begin{tabular}{|c|c|c|c|c|c|c|c|c|c|c|c|c|c|}
\hline & \multicolumn{2}{|c|}{ Manufacturer } & \multicolumn{4}{|l|}{ Study } & \multicolumn{3}{|c|}{ CI for $x_{1}-\mathrm{X}_{2}$} & \multicolumn{4}{|c|}{ Two-Sample Pooled T-Test } \\
\hline NR Value & $\mathrm{NR}\left(\mathrm{x}_{1}\right)$ & $\mathrm{SD}\left(\mathrm{s}_{1}\right)^{*}$ & $\mathrm{NR}\left(\mathrm{x}_{2}\right)$ & $\mathrm{SD}\left(\mathrm{s}_{2}\right)$ & $s_{p}$ & $\mathrm{PE}$ & LCL & UCL & $\mathrm{LCL}>0$ & $\mathrm{t}_{\text {critical }}$ & $t_{\text {actual }}$ & $\mathrm{P}_{\text {value }}$ & Reject Null \\
\hline NR Linear & 12.2 & 1.5 & 7.2 & 1.5 & 1.5 & 5.0 & 4.0 & 6.1 & Y & 2.035 & 9.5 & $2.6 \mathrm{E}-11$ & Y \\
\hline NR C-Weighted & 12.0 & 1.6 & 7.1 & 1.6 & 1.6 & 4.9 & 3.8 & 6.0 & $\mathrm{Y}$ & 2.035 & 9.2 & $6.3 \mathrm{E}-11$ & $\mathrm{Y}$ \\
\hline NR A-Weighted & 19.4 & 1.5 & 11.2 & 1.5 & 1.5 & 8.2 & 7.1 & 9.3 & $\mathrm{Y}$ & 2.035 & 15.8 & $2.8 \mathrm{E}-17$ & $\mathrm{Y}$ \\
\hline
\end{tabular}

Mid Frequency Noise Spectrum (Howell and Martin, 1975)

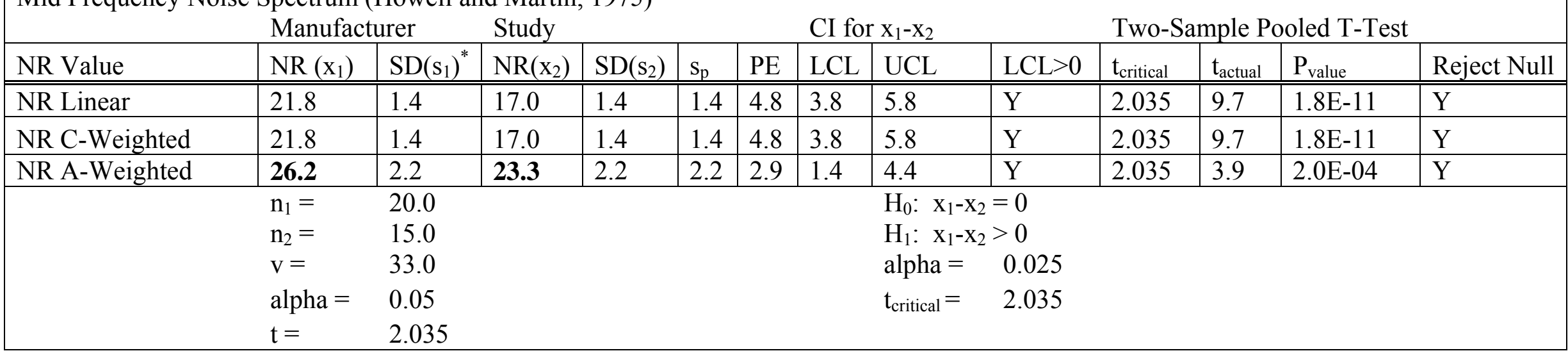

* Variance for the manufacturer is assumed to equal that of the study data. Because overall NR values were calculated there is no available variance data for the manufacturer. 
Table 6. Statistical Analysis of Overall Attenuation Values - Peltor H10A Earmuff Pink Noise Spectrum

\begin{tabular}{|c|c|c|c|c|c|c|c|c|c|c|c|c|c|}
\hline \multicolumn{3}{|c|}{ Manufacturer } & \multicolumn{4}{|l|}{ Study } & \multicolumn{3}{|c|}{ CI for $\mathrm{x}_{1}-\mathrm{x}_{2}$} & \multicolumn{4}{|c|}{ Two-Sample Pooled T-Test } \\
\hline NR Value & $\operatorname{NR}\left(\mathrm{x}_{1}\right)$ & $\mathrm{SD}\left(\mathrm{s}_{1}\right)^{*}$ & $\mathrm{NR}\left(\mathrm{x}_{2}\right)$ & $\mathrm{SD}\left(\mathrm{s}_{2}\right)$ & $\mathrm{s}_{\mathrm{p}}$ & $\mathrm{PE}$ & $\mathrm{LCL}$ & UCL & $\mathrm{LCL}>0$ & $\mathrm{t}_{\text {critical }}$ & $t_{\text {actual }}$ & $P_{\text {value }}$ & Reject Null \\
\hline NR Linear & 29.1 & 1.2 & 22.9 & 1.2 & 1.2 & 6.2 & 5.4 & 7.0 & $\mathrm{Y}$ & 2.032 & 15.2 & $5.4 \mathrm{E}-17$ & $\mathrm{Y}$ \\
\hline NR C-Weighted & 28.6 & 1.2 & 22.6 & 1.2 & 1.2 & 6.0 & 5.1 & 6.8 & $\mathrm{Y}$ & 2.032 & 14.6 & $1.7 \mathrm{E}-16$ & $\mathrm{Y}$ \\
\hline NR A-Weighted & 37.8 & 2.9 & 32.4 & 2.9 & 2.9 & 5.4 & 3.4 & 7.4 & $\mathrm{Y}$ & 2.032 & 5.6 & $1.5 \mathrm{E}-06$ & $\mathrm{Y}$ \\
\hline NRR & 35.0 & 2.9 & 30.2 & 2.9 & 2.9 & 4.8 & 2.9 & 6.8 & Y & 2.032 & 5.0 & $9.0 \mathrm{E}-06$ & $\mathrm{Y}$ \\
\hline
\end{tabular}

Low Frequency Noise Spectrum (47'MLB)

\begin{tabular}{|l|l|l|l|l|l|l|l|l|l|l|l|l|l|l|}
\multicolumn{1}{c}{ Manufacturer } & \multicolumn{1}{c}{ Study } & Two-Sample Pooled T-Test \\
\hline NR Value & $\mathrm{NR}\left(\mathrm{x}_{1}\right)$ & $\mathrm{SD}\left(\mathrm{s}_{1}\right)^{*}$ & $\mathrm{NR}\left(\mathrm{x}_{2}\right)$ & $\mathrm{SD}\left(\mathrm{s}_{2}\right)$ & $\mathrm{s}_{\mathrm{p}}$ & $\mathrm{PE}$ & $\mathrm{LCL}$ & $\mathrm{UCL}$ & $\mathrm{LCL}>0$ & $\mathrm{t}_{\text {critical }}$ & $\mathrm{t}_{\text {actual }}$ & $\mathrm{P}_{\text {value }}$ & Reject Null \\
\hline \hline NR Linear & 22.1 & 1.3 & 16.6 & 1.3 & 1.3 & 5.5 & 4.7 & 6.4 & $\mathrm{Y}$ & 2.032 & 13.0 & $4.4 \mathrm{E}-15$ & $\mathrm{Y}$ & \\
\hline NR C-Weighted & 22.0 & 1.3 & 16.6 & 1.3 & 1.3 & 5.4 & 4.5 & 6.3 & $\mathrm{Y}$ & 2.032 & 12.5 & $1.3 \mathrm{E}-14$ & $\mathrm{Y}$ & \\
\hline NR A-Weighted & $\mathbf{2 9 . 5}$ & $\mathbf{1 . 6}$ & 21.0 & 1.6 & 1.6 & 8.6 & 7.5 & 9.6 & $\mathrm{Y}$ & 2.032 & 16.4 & $5.4 \mathrm{E}-18$ & $\mathrm{Y}$ \\
\hline \hline
\end{tabular}

Mid Frequency Noise Spectrum (Howell and Martin, 1975)

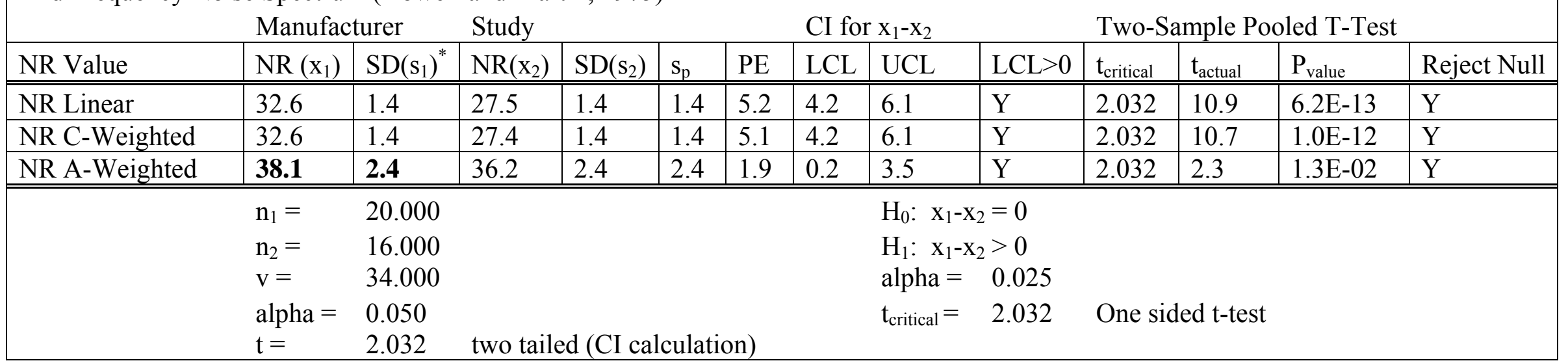

* Variance for the manufacturer is assumed to equal that of the study data. Because overall NR values were calculated there is no available variance data for the manufacturer. 
It must also be noted that as the overall sound level becomes increasingly dominated by the mid and high frequency ranges, the MSA Sordin Supreme Pro, with amplification activated, performs increasingly poorly with respect to noise reduction (Table 7). This is due to the fact that the maximum amplification occurs in the middle to high frequencies. Use of the MSA Sordin Supreme Pro headset with amplification activated in any of the various spectrums presented could result in increased exposure for some individuals. The OB mean noise reduction goes from $6.7 \mathrm{dBA}$ to $0.2 \mathrm{dBA}$ as the noise spectrum becomes more high frequency dominant. This feature partially and sometimes fully offsets the noise reduction capability of the headset in most of the mid to high frequency range.

Table 7. MSA Sordin Supreme Pro Headset Octave Band Noise Reduction

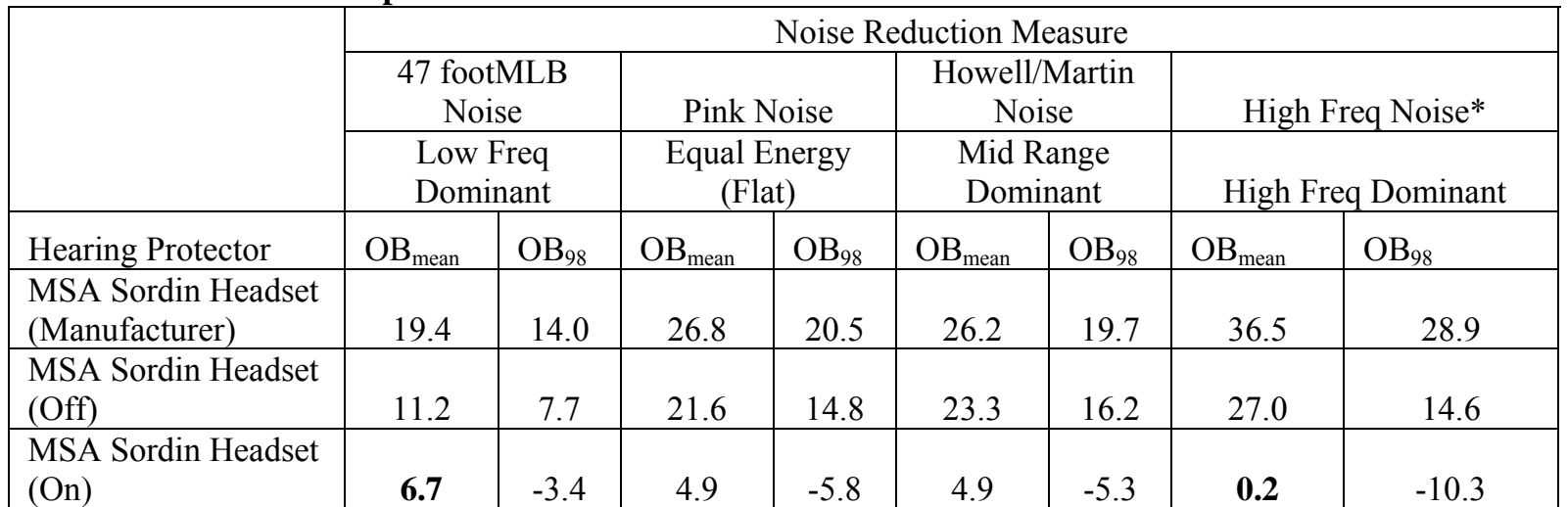

*OB values calculated using the high frequency noise field depicted in Figure 2.

This study found that use of the amplification feature will expose some individuals to unacceptable levels of continuous noise. This is consistent with the findings of previous studies which have shown that while amplitude-sensitive sound transmission capability is effective in intermittent noise environments, especially those with impulse noise (rifle ranges), it may cause annoyance and create exposure risk in continuous high-level noise environments (Berger, 2003; Casali and Berger, 1996).

This phenomenon increases as the noise spectrum becomes more dominated by sound energy in the mid and high ranges of the frequency spectrum. For example, helicopter noise is dominated by pressure spikes in the mid to high frequency ranges caused by turbine fan harmonics and by the tail rotor due to rotating force on the blades and the displacement of air due to the blade section area (FAA, 1975). Use of the headset amplification feature during helicopter operations will expose personnel to an extreme noise hazard and additionally may render communications useless. Additionally, due to the extreme noise levels when conducting helicopter operations, personnel would be required to wear double hearing protection. Ear plugs worn under the headset will have an effect on communications since the plug will attenuate the headset signal as well as ambient noise. The extent of the effect that secondary hearing protection would have on speech intelligibility is an issue that warrants further study. 
It must be noted that the wireless communications system works properly without the headset amplification turned on. The two features are independent. The amplification feature simply amplifies ambient noise around the headset. It has no effect on the wireless signal transmitted via the transceivers. The results from this study suggest that in a continuous noise environment workers should not utilize the headset amplification feature.

\section{Sources of Discrepancy between Study Data and Manufacturer Data}

Several factors may contribute to the discrepancy between the study data and the manufacturer data. The first possibility is leakage caused by the microphone wire passing under the ear cup to record the sound level inside the protector. This systematic bias would lead to a reduction in the attenuation values in some frequency bands. As a result of the very small wire size passing under the muff material, it is believed that this bias was negligible.

Another source of error may have been the use of MIRE/NR instead of the more accurate IL value. As discussed previously, the NR value actually underestimates the true reduction due to the TFOE. All else being equal, one would expect lower NR values in the human speech frequency range when compared to REAT or MIRE/IL values. Instead this study found the opposite. From $500-2000 \mathrm{~Hz}$, which overlaps with the human speech range of $1000-4000 \mathrm{~Hz}$, the NR values increased and actually overlapped with the manufacturer REAT IL values. But this could be due to bone conduction influences present in the REAT data (see below). Therefore, the use of NR vs. IL likely does have some effect on the discrepancy between the study data and the manufacturer data, at least partially accounting for the lower noise reduction values found in this study.

Another source of discrepancy may be the physical measures employed by the MIRE method versus the psychophysical measures used by the REAT method. As discussed previously, research has shown that REAT can over-estimate noise reduction in the lower frequency ranges due to masking effects of physiological noise, while the MIRE does not account for the effect of bone conduction, a pathway that influences a person's overall exposure as a flanking route around the HPD to the middle ear. In particular, research has shown that the bone conduction threshold is lowest at $2000 \mathrm{~Hz}$, and that this flanking pathway to the inner ear may correctly lower protected thresholds in the mid frequency range in psychophysical tests. This effect would not be picked up by MIRE methodology since measurement is made in the outer ear, potentially leading to artificially high noise reduction values in the mid-frequency ranges. This results in lower REAT noise reduction values at $500 \mathrm{~Hz}$ and above when compared to MIRE data (Casali et al., 1995). This may account somewhat for the overlap observed in the 500-2000 Hz range.

\section{Clamp Force Discussion}

The objective of the clamp force/noise reduction comparison was to determine the relationship between increasing clamp force and increasing noise reduction. 
Figure 18. MSA Sordin Headset: Noise Reduction vs. Clamp Force

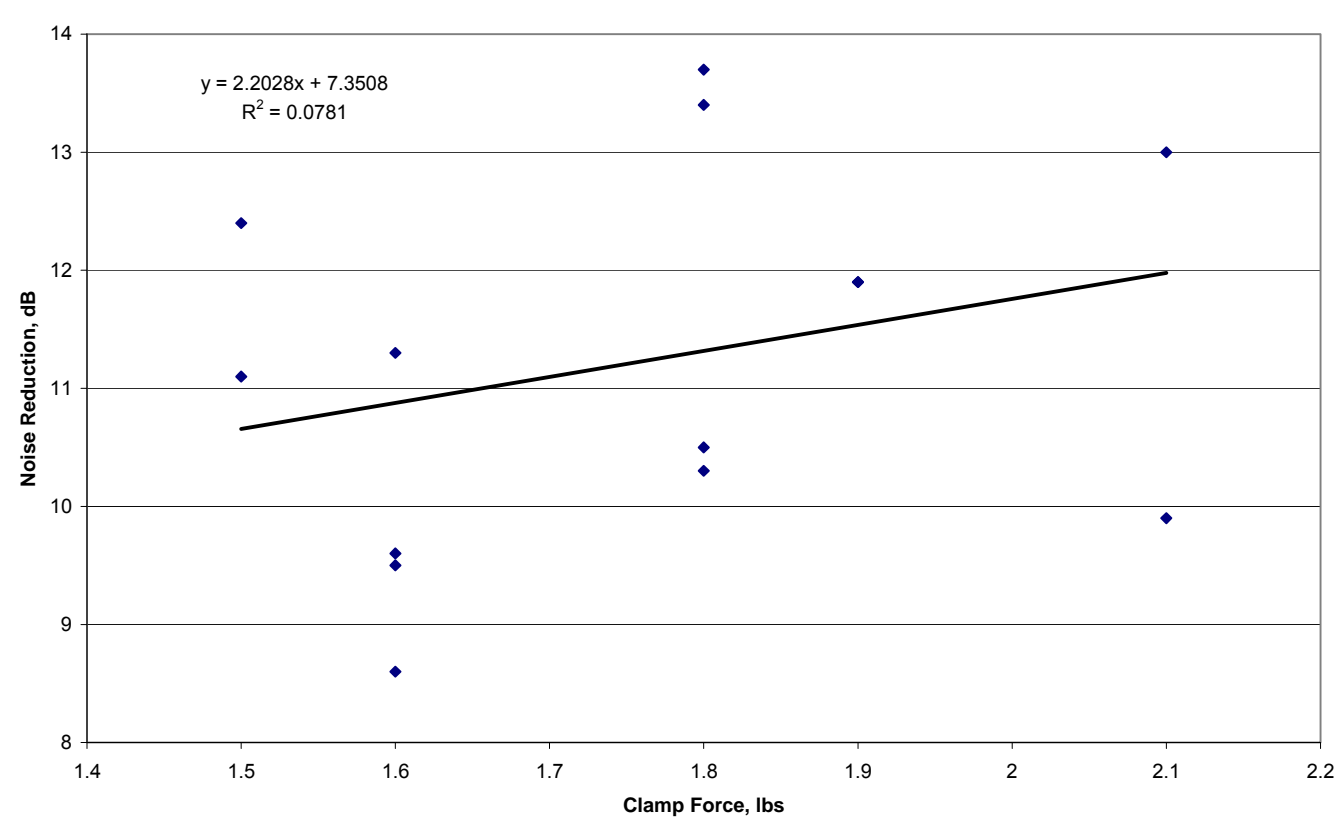

Figure 19. Peltor H10A: Noise Reduction vs. Clamp Force

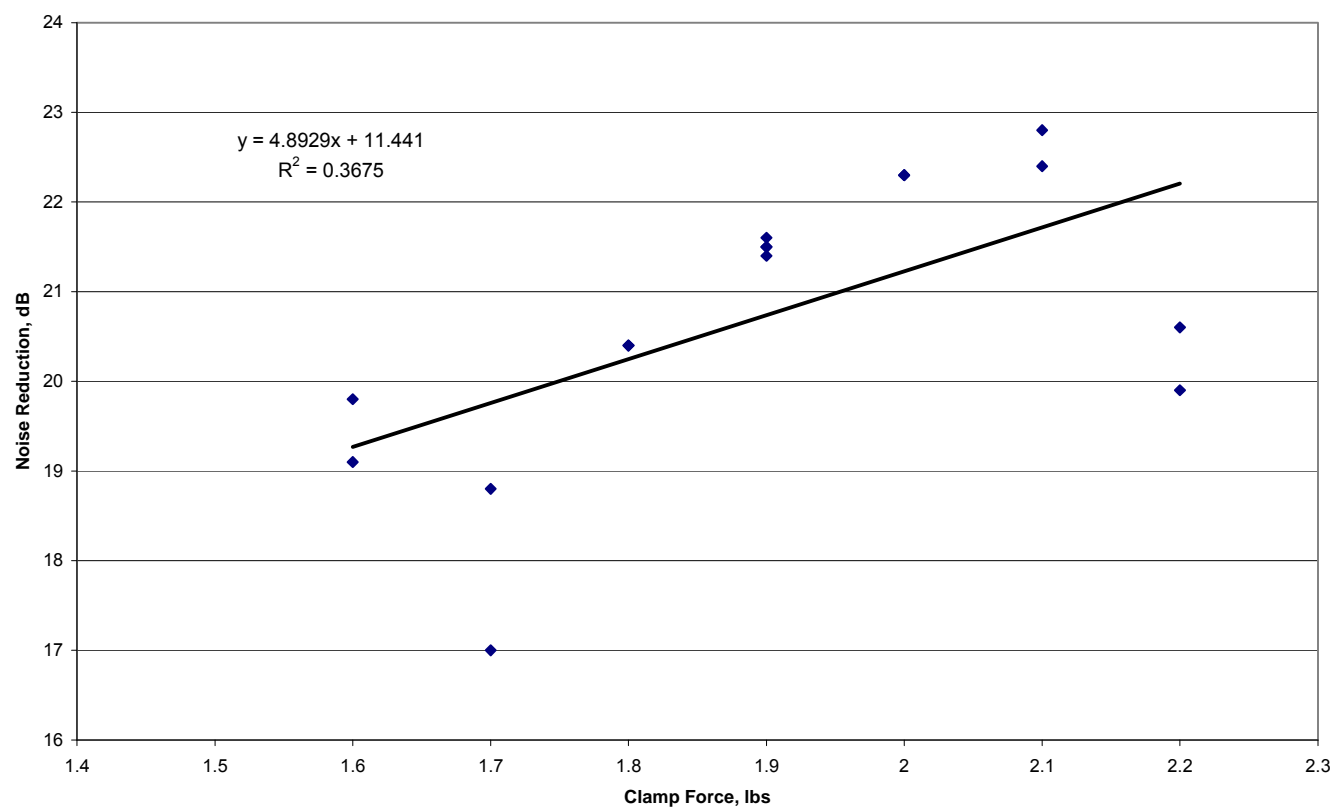

Figures 18 and 19 show noise reduction plotted against clamp force for the MSA Sordin headset and the Peltor H10A earmuff respectively. The noise reduction numbers used in these two figures are OB values calculated for each subject. MSA Sordin data is "amplification off". Each subject was tested twice which accounts for the number of data points. For the MSA Sordin plot (Figure 18) Subject 7's data was not included. Figure 19 does include Subject 7 since he received a proper seal with the Peltor earmuff. The correlation for the Peltor earmuff is stronger $\left(\mathrm{R}^{2}=0.3675\right)$ than the MSA Sordin headset $\left(\mathrm{R}^{2}=0.078\right)$, which indicates that clamp force was probably irrelevant to noise reduction. 
Table 8. MSA Sordin/Clamp Force Analysis

\begin{tabular}{|c|c|c|c|c|c|c|}
\hline \multirow{2}{*}{$\begin{array}{l}\text { Subject } \\
1 \mathrm{a}\end{array}$} & $\begin{array}{l}\text { MSA Clamp } \\
\text { Force (lbs) } \\
\end{array}$ & $\left(x_{i}-x\right)^{2}$ & $\begin{array}{l}\text { MSA Sordin } \\
\text { NR (OB), dB } \\
\end{array}$ & $\left(y_{i}-y\right)^{2}$ & \multicolumn{2}{|c|}{$\begin{array}{l}\text { MSA Sordin } \\
(\mathrm{xi}-\mathrm{x})(\mathrm{yi}-\mathrm{y}) \\
\end{array}$} \\
\hline & 2.1 & 0.117551 & 13.0 & 3.163316 & & 0.6 \\
\hline $1 \mathrm{~b}$ & 2.1 & 0.117551 & 9.9 & 1.746173 & & -0.5 \\
\hline $2 \mathrm{a}$ & 1.8 & 0.001837 & 10.3 & 0.849031 & & 0.0 \\
\hline $2 b$ & 1.8 & 0.001837 & 10.5 & 0.520459 & & 0.0 \\
\hline $3 \mathrm{a}$ & 1.9 & 0.020408 & 11.9 & 0.460459 & & 0.1 \\
\hline $3 b$ & 1.9 & 0.020408 & 11.9 & 0.460459 & & 0.1 \\
\hline $4 a$ & 1.6 & 0.024694 & 9.5 & 2.963316 & & 0.3 \\
\hline $4 b$ & 1.6 & 0.024694 & 9.6 & 2.629031 & & 0.3 \\
\hline $5 a$ & 1.8 & 0.001837 & 13.4 & 4.746173 & & 0.1 \\
\hline $5 b$ & 1.8 & 0.001837 & 13.7 & 6.143316 & & 0.1 \\
\hline $6 a$ & 1.6 & 0.024694 & 8.6 & 6.871888 & & 0.4 \\
\hline $6 \mathrm{~b}$ & 1.6 & 0.024694 & 11.3 & 0.006173 & & 0.0 \\
\hline \multicolumn{7}{|l|}{$7 \mathrm{a}$} \\
\hline \multicolumn{7}{|l|}{$7 b$} \\
\hline $8 \mathrm{a}$ & 1.5 & 0.066122 & 11.1 & 0.014745 & & 0.0 \\
\hline $8 b$ & 1.5 & 0.066122 & 12.4 & 1.389031 & & -0.3 \\
\hline $\operatorname{Avg}=$ & 1.75714286 & Avg $=$ & 11.2214 & & & \\
\hline & $\mathrm{S}_{\mathrm{xx}}=$ & 0.514286 & $\mathrm{~S}_{\mathrm{yy}}=$ & 31.96357 & $S_{x y}=$ & 1.1 \\
\hline \multicolumn{7}{|c|}{$\mathrm{r}=\mathrm{S}_{\mathrm{xy}} /\left(\mathrm{S}_{\mathrm{xx}} \mathrm{S}_{\mathrm{yy}}\right)^{0.5}$} \\
\hline \multicolumn{7}{|c|}{ MSA Sordin/Clamp Force Correlation Coefficient, $r=$} \\
\hline & $\mathrm{H}_{0}:$ & $\mathrm{r}=0$ & \multicolumn{2}{|c|}{$\mathrm{n}_{\mathrm{MSA}}=14$} & $\mathrm{df}_{\mathrm{MSA}}=$ & 12 \\
\hline & $\mathrm{H}_{1}$ : & $\mathrm{r}>0$ & & & & \\
\hline & $\alpha=$ & 0.05 & & & & \\
\hline & $\mathrm{t}=$ & 1.356217 & & & & \\
\hline & Critical Region: & $\mathrm{t}>1.356$ & & & & \\
\hline & Actual $t_{\mathrm{MSA}}=$ & 1.457237 & & & & \\
\hline & $\mathrm{P}=$ & 0.085359 & & & & \\
\hline
\end{tabular}

Table 8 outlines the steps to calculate the correlation coefficient between the MSA Sordin headset NR and clamp force. Solving for $\mathrm{r}$, the MSA/clamp force correlation coefficient is $0.28\left(\mathrm{r}^{2}=0.078\right.$, verifies with the regression plot, Figure 18). This is indicative of a very weak relationship; the correlation is not significant $(p$-value $=0.085)$.

The Peltor analysis is found in Table 9. The Peltor/clamp force correlation coefficient, $r$, is 0.61 , a stronger positive relationship $\left(r^{2}=0.368\right.$, see Figure 19). The $p$-value $=0.006$ indicates that the correlation is statistically significant. 
Table 9. Peltor/Clamp Force Analysis

\begin{tabular}{|c|c|c|c|c|c|c|}
\hline Subject & $\begin{array}{l}\text { Peltor Clamp } \\
\text { Force (lbs) } \\
\end{array}$ & $\left(x_{i}-x\right)^{2}$ & Peltor NR (OB), dB & $\left(y_{i}-y\right)^{2}$ & \multicolumn{2}{|c|}{$\begin{array}{l}\text { Peltor } \\
(x i-x)(y i-y)\end{array}$} \\
\hline $1 \mathrm{a}$ & 2.2 & 0.09 & 19.9 & 0.701406 & & $\overline{0} .3$ \\
\hline $1 \mathrm{~b}$ & 2.2 & 0.09 & 20.6 & 0.018906 & & 0.0 \\
\hline $2 \mathrm{a}$ & 1.9 & $1.97 \mathrm{E}-31$ & 21.4 & 0.438906 & & 0.0 \\
\hline $2 b$ & 1.9 & $1.97 \mathrm{E}-31$ & 21.5 & 0.581406 & & 0.0 \\
\hline $3 \mathrm{a}$ & 2.0 & 0.01 & 22.3 & 2.441406 & & 0.2 \\
\hline $3 b$ & 2.0 & 0.01 & 22.3 & 2.441406 & & 0.2 \\
\hline $4 a$ & 1.7 & 0.04 & 18.8 & 3.753906 & & 0.4 \\
\hline $4 b$ & 1.7 & 0.04 & 17.0 & 13.96891 & & 0.7 \\
\hline $5 \mathrm{a}$ & 1.9 & $1.97 \mathrm{E}-31$ & 21.6 & 0.743906 & & 0.0 \\
\hline $5 b$ & 1.9 & $1.97 \mathrm{E}-31$ & 21.5 & 0.581406 & & 0.0 \\
\hline $6 \mathrm{a}$ & 1.8 & 0.01 & 20.4 & 0.113906 & & 0.0 \\
\hline $6 \mathrm{~b}$ & 1.8 & 0.01 & 20.4 & 0.113906 & & 0.0 \\
\hline $7 \mathrm{a}$ & 2.1 & 0.04 & 22.8 & 4.253906 & & 0.4 \\
\hline $7 b$ & 2.1 & 0.04 & 22.4 & 2.763906 & & 0.3 \\
\hline $8 \mathrm{a}$ & 1.6 & 0.09 & 19.1 & 2.681406 & & 0.5 \\
\hline $8 \mathrm{~b}$ & 1.6 & 0.09 & 19.8 & 0.878906 & & 0.3 \\
\hline $\operatorname{Avg}=$ & 1.9 & $\operatorname{Avg}=$ & 20.7375 & & & \\
\hline & $\mathrm{S}_{\mathrm{xx}}=$ & 0.56 & $\mathrm{~S}_{\mathrm{yy}}=$ & 36.4775 & $\mathrm{~S}_{\mathrm{xy}}=$ & 2.7 \\
\hline
\end{tabular}

Peltor/Clamp Force Correlation Coefficient, $r=0.60624$

$\begin{aligned} \mathrm{H}_{0}: & \mathrm{r}=0 \\ \mathrm{H}_{1}: & \mathrm{r}>0 \\ \alpha= & 0.05 \\ \mathrm{t}= & 1.34503 \\ \text { Critical Region: } & \mathrm{t}>1.345 \\ \text { Actual toeltor } & 2.852244 \\ \mathrm{P}= & 0.006397\end{aligned}$

The range of clamp force for both hearing protectors was the same indicating that the difference in NR between the two protectors was not due to clamp force. This also indicates that a lack of clamping force was not the reason for the lower noise reduction data achieved by the MSA Sordin headset. Although a weak positive relationship was detected between NR and clamp force, it was not significant enough to state conclusively that noise reduction is a function of clamp force. 


\section{Conclusions}

This study resulted in the following conclusions:

1. The communications system consisting of the MSA Sordin Supreme Pro headset and the Trulink $^{\mathrm{TM}}$ wireless intercommunications system significantly improved communications for personnel in all tested ambient noise levels.

2. Depending on the frequency distribution of the environmental noise, the MSA Sordin Octave Band NR ranged from 11.2 to $27 \mathrm{dBA}$ with the low end of the range corresponding with low frequency dominant noise.

3. One of the key findings of this study was the effect that the headset amplification feature had on the overall protected exposure. The headset amplification feature drastically reduces the noise reducing capability of the MSA Sordin headset. This effect is maximized in high frequency, continuous noise meaning that personnel will be overexposed to hazardous levels of noise when the amplification feature is activated.

4. As previously discussed, one subject could not receive a proper seal using the MSA Sordin Supreme Pro headset. This represented 1 out of 8 subjects tested. This ratio can not be interpolated to the general population due to the small sample size, but it does signal the need to properly fit test all individuals who will be using this headset. Further study with significantly larger sampling is required to determine exactly how widespread this phenomenon may be. A deeper cushion would mitigate the problem, but the effects of such a cushion on the headset electronics would have to be evaluated.

\section{Limitations}

The conclusions in this study strictly apply to the test conditions as outlined in this report. As demonstrated, the MSA Sordin headset will provide differing levels of protection depending on the actual environmental noise spectrum. The spectrum and overall noise level also determine the degree of noise reduction degradation experienced when utilizing the amplification feature.

The overall protection being provided by the MSA Sordin Supreme Pro headset or any other HPD will vary depending on the actual noise spectrum of the intended environment. The low frequency noise spectrum used in this study was recorded onboard a CG 47 foot MLB. This was the only spectrum representing an actual work environment. The other spectra were artificially created or taken from literature. 


\section{Recommendations}

In conjunction with the conclusions listed above, the following recommendations are advised:

1. The MSA Sordin headset amplification feature should not be activated in continuous noise, especially high frequency, continuous noise.

2. Because the headset will provide most users with less than the advertised NRR of 18 $\mathrm{dB}$, constant evaluation of the noise environment is required to ensure that personnel are not over-exposed.

3. All personnel who will be using this headset and communication system must be fit tested to ensure a proper seal.

4. All personnel who will be using this headset and communication system must be trained in its proper use.

5. In noise levels $>95 \mathrm{dBA}$ double hearing protection will be required to ensure that personnel are not over-exposed. This is particularly critical during helicopter operations or any other operation in a continuous, high frequency noise environment. 


\section{References}

ANSI S12.6-1997. (1997) American National Standard Methods for Measuring the RealEar Attenuation of Hearing Protectors. New York, NY: American National Standards Institute, Inc.

ANSI S3.19-1974. (1974) American National Standard: method for the measurement of real-ear protection of hearing protectors and physical attenuation of ear muffs. New York, NY: American National Standards Institute, Inc.

Behar A. (1985) Field evaluation of hearing protectors. Noise Control Eng J; 24: 13-8.

Berger EH. (2003) Chapter 10: Hearing protection devices. In: Berger EH, Royster LH, Royster JD, Driscoll DP, Layne ML, editors. The Noise Manual. 5th edn. US: American Industrial Hygiene Association. pp. 379-454.

Berger EH, Franks JR, Lindgren F. (1996) International review of field studies of hearing protector attenuation. In: Axlesson A, Borchgrevink H, Hamernik RP, Hellstrom P, Henderson D, Salvi RJ, editors. Scientific basis of noise-induced hearing loss. New York, NY: Thieme Medical Publishers, Inc. pp. 361-77.

Berger EH, Mitchell I. (1989) Measurement of the Pressure Exerted by Earmuffs and its Relationship to Perceived Comfort. Applied Acoustics. 27: 79-88.

Berger EH. (1986) Methods of measuring the attenuation of hearing protection devices. J Acoust Soc Am; 79: 1655-87.

Berger EH. (1983) Laboratory Attenuation of Earmuffs and Earplugs Both Singly and in Combination. Am. Ind. Hyg. Assoc. J., 44(5): 321-329.

Berger EH, Kerivan JE. (1983) Influence of physiological noise and the occlusion effect on the measurement of real-ear attenuation at threshold. J Acoust Soc Am. 74: 81-94.

Casali JG, Berger EH. (1996) Technology Advancements in Hearing Protection Circa 1995: Active Noise Reduction, Frequency/Amplitude-Sensitivity, and Uniform Attenuation. J. Am. Ind. Hyg. Assoc., 57(2): 175-185.

Casali J, Mauney D, Burks JA. (1995) Physical vs. psychophysical measurement of hearing protector attenuation - a.k.a. MIRE vs. REAT. J Sound Vib; 29: 20-7.

Casali J, Park M. (1991) Laboratory versus field attenuation of selected hearing protectors. J Sound Vib; 25: 28-38.

Casali JG, Grenell JF. (1990) Noise-Attenuating Earnuff Comfort: A Brief review and Investigation of Band Force, Cushion and Wearing-Time Effects. Applied Acoustics. 29: $117-138$.

Casali JG, Grenell JF. (1989) An Exploratory Study of Moderate Physical Activity and Selected Design Attribute Effects on Earmuff Attenuation. Am. Ind. Hyg. Assoc. J., 50(9): 480-485.

EPA. (1979) Noise Labeling Requirements for Hearing Protectors. In: Fed Regist 44(190), 40. Washington, DC: Environmental Protection Agency. pp. 130-56, 147.

FAA (1975). A Comprehensive Review of Helicopter Noise Literature. Federal Aviation Administration, Systems Research and Development Service, Washington D.C.

Flugrath JM, Wolfe BN. (1971) The Effectiveness of Selected Earmuff Type Hearing Protectors. Sound and Vibration. 5(5): 25-27.

Giardino DA, Durkt G. (1996) Evaluation of Muff-Type Hearing Protectors as used in a Working Environment. J. Am. Ind. Hyg. Assoc; 57(3): 264-271. 
Howell K, Martin AM. (1975). An Investigation of the Effects of Hearing Protectors on Vocal Communication in Noise. J. Sound Vib. 41(2): 181-196.

Krietemeyer GE. (1991) The Coast Guardsman's Manual. 8th Edition, Naval Institute Press.

Kryter KD. (1946) Effects of Ear Protective Devices on the Intelligibility of Speech in Noise. J Acoust Soc Am., 18: 413-417.

Neitzel R, Somers S, Seixas N. (2006) Variability of Real-World Hearing Protector Attenuation Measurements. Ann. Occup. Hyg. June 16, 2006: 1-13.

Nilsson M, Soli SD, Sullivan JA. (1994) Development of the Hearing in Noise Test for the Measurement of Speech Reception Thresholds in Quiet and in Noise. J. Acoust. Soc. Am., 95(2): 1085-1099.

Pollack I. (1957) Speech Communication at High Noise Levels; the Roles of a Noise Operated Automatic Gain Control System and Hearing Protection. J. Acoust. Soc. Am., 29: 1324-1327.

Steeneken HJM, Houtgast T. (1980) A Physical Method for Measuring SpeechTransmission Quality. J. Acoust. Soc. Am. 67(1): 318-326.

Stewart A. (2000) Chapter 6: Program overview and administration. In: Berger EH, Royster LH, Royster JD, Driscoll DP, Layne ML, editors. The noise manual. 5th edn. US: American Industrial Hygiene Association. pp. 150-64.

USCG (2006). 47 footMLB Crew Communications System Functional Requirements Document. Washington DC: US Department of Homeland Security, United States Coast Guard.

USCG (2002). Report of 47 footMLB Noise Assessment and Hearing Protection Device Study. Alameda CA: US Department of Homeland Security, United States Coast Guard, ISC Alameda Safety and Environmental Health Office.

USCG (1990). US Coast Guard Noise Standard (COMDTINST 5100.47). Washington DC: US Department of Homeland Security, United States Coast Guard.

Wagoner L, McGlothlin J, Chung K, Strickland E, Zimmerman N, Carlson G. (2007) Evaluation of Noise Attenuation and Verbal Communication Capabilities Using Three Ear Insert Hearing Protection Systems Among Airport Maintenance Personnel. J. Occup and Env Hyg. 4: 114-122. 


\section{Appendix A. Sample Calculations and Tables}

Table A1. NRR Calculation - Manufacturer Data

\begin{tabular}{|l|l|c|c|c|c|c|c|c|c|c|c|}
\hline Line & Frequency, $\mathrm{Hz}$ & 125 & 250 & 500 & 1000 & 2000 & 4000 & 6300 & 8000 & SPL & NRR $* * *$ \\
\hline 1 & Ambient Pink Noise, dB & 100 & 100 & 100 & 100 & 100 & 100 & 100 & 100 & & \\
\hline 2 & $\begin{array}{l}\text { C-Weighting Corrections, } \\
\text { dB }\end{array}$ & -0.2 & 0 & 0 & 0 & -0.2 & -0.8 & -2 & -3 & & \\
\hline 3 & $\begin{array}{l}\text { C-Weighted Unprotected } \\
\text { Pink Noise, dBC }\end{array}$ & 99.8 & 100.0 & 100.0 & 100.0 & 99.8 & 99.2 & 98.0 & 97.0 & 108.4 & \\
\hline 4 & $\begin{array}{l}\text { A-Weighting Corrections, } \\
\text { dB }\end{array}$ & -16.1 & -8.6 & -3.2 & 0.0 & 1.2 & 1.0 & -0.1 & -1.1 & & \\
\hline 5 & $\begin{array}{l}\text { A-Weighted Pink Noise, } \\
\text { dBA }\end{array}$ & 83.9 & 91.4 & 96.8 & 100.0 & 101.2 & 101.0 & 99.9 & 98.9 & & \\
\hline 6 & Avg Attenuation, dB & 11.1 & 16.5 & 23.1 & 25.0 & 29.5 & 35.5 & 38.3 & 38.7 & & \\
\hline 7 & Std Dev & 2.6 & 3.0 & 3.2 & 2.8 & 4.1 & 3.6 & 4.0 & 3.2 & & \\
\hline 8 & Std Dev x 2 & 5.2 & 6.0 & 6.4 & 5.6 & 8.2 & 7.2 & 8.0 & 6.4 & & \\
\hline 9 & $\begin{array}{l}\text { Average Protection Value } \\
\text { APV) }\end{array}$ & 5.9 & 10.5 & 16.7 & 19.4 & 21.3 & 28.3 & 30.3 & 32.3 & & \\
\hline 10 & $\begin{array}{l}\text { Protected Ear A-Weighted - } \\
\text { SPL** }\end{array}$ \\
\hline
\end{tabular}

Table A2. Noise Reduction Calculations: Unweighted, C-Weighted, A-Weighted, and Octave-Band Method (NIOSH Method \#1) using 47 footMLB noise spectrum with Manufacturer Data.

\begin{tabular}{|c|c|c|c|c|c|c|c|c|c|c|c|}
\hline Line & Frequency, $\mathrm{Hz}$ & 125 & 250 & 500 & 1000 & 2000 & 4000 & 6300 & 8000 & SPL & NR \\
\hline 1 & $\begin{array}{l}\text { Ambient } 47 \text { footMLB noise, } \\
\text { dB }\end{array}$ & 103.9 & 95.3 & 86.4 & 90.2 & 86.4 & 81.0 & 85.8 & 94.3 & 105.2 & \\
\hline 2 & Avg Attenuation, dB & 11.1 & 16.5 & 23.1 & 25.0 & 29.5 & 35.5 & 38.3 & 38.7 & & Unweighted \\
\hline 3 & Protected Noise, $\mathrm{dB}$ & 92.8 & 78.8 & 63.3 & 65.2 & 56.9 & 45.5 & 47.5 & 55.6 & 93.0 & 12.2 \\
\hline 4 & C-Weighting Corrections, $\mathrm{dB}$ & -0.2 & 0.0 & 0.0 & 0.0 & -0.2 & -0.8 & -2.0 & -3.0 & & \\
\hline 5 & $\begin{array}{l}\text { C-Weighted Unprotected } \\
\text { Noise, dBC }\end{array}$ & 103.7 & 95.3 & 86.4 & 90.2 & 86.2 & 80.2 & 83.8 & 91.3 & 104.8 & C-Weighted \\
\hline 6 & $\begin{array}{l}\text { C-Weighted Protected Noise, } \\
\text { dB }\end{array}$ & 92.6 & 78.8 & 63.3 & 65.2 & 56.7 & 44.7 & 45.5 & 52.6 & 92.8 & 12.0 \\
\hline 7 & A-Weighting Corrections, $\mathrm{dB}$ & -16.1 & -8.6 & -3.2 & 0.0 & 1.2 & 1.0 & -0.1 & -1.1 & & \\
\hline 8 & $\begin{array}{l}\text { A-Weighted Unprotected } \\
\text { Noise, dBA }\end{array}$ & 87.8 & 86.7 & 83.2 & 90.2 & 87.6 & 82.0 & 85.7 & 93.2 & 97.4 & A-Weighted \\
\hline 9 & $\begin{array}{l}\text { A-Weighted Protected Noise, } \\
\text { dB }\end{array}$ & 76.7 & 70.2 & 60.1 & 65.2 & 58.1 & 46.5 & 47.4 & 54.5 & 78.0 & 19.4 \\
\hline 10 & Avg Attenuation, dB & 11.1 & 16.5 & 23.1 & 25.0 & 29.5 & 35.5 & 38.3 & 38.7 & & \\
\hline 11 & Std Dev & 2.6 & 3.0 & 3.2 & 2.8 & 4.1 & 3.6 & 4.0 & 3.2 & & \\
\hline 12 & Std Dev x 2 & 5.2 & 6.0 & 6.4 & 5.6 & 8.2 & 7.2 & 8.0 & 6.4 & & \\
\hline 13 & $\begin{array}{l}\text { Average Protection Value } \\
\text { (APV)* }\end{array}$ & 5.9 & 10.5 & 16.7 & 19.4 & 21.3 & 28.3 & 30.3 & 32.3 & & $\mathrm{OB}_{98}$ \\
\hline 14 & $\begin{array}{l}\text { Protected Ear A-Weighted } \\
\text { SPL** }\end{array}$ & 81.9 & 76.2 & 66.5 & 70.8 & 66.3 & 53.7 & 55.4 & 60.9 & 83.4 & 14.0 \\
\hline & \multicolumn{9}{|c|}{$* \mathrm{APV}=$ Avg. Attenuation -2 Std Dev $=$ Line $10-$ Line 12} & & \\
\hline & \multicolumn{10}{|c|}{ ** Protected Ear A-Weighted SPL $=$ A-Weighted Unprotected Noise, $\mathrm{dBA}-\mathrm{APV}=$ Line $8-$ Line 13} & \\
\hline
\end{tabular}




\section{Appendix B. Data Tables and Figures with Subject 7 Included.}

Figure B1. NR Statistical Comparison: Amplification On vs. Amplification Off (With Subject 7)

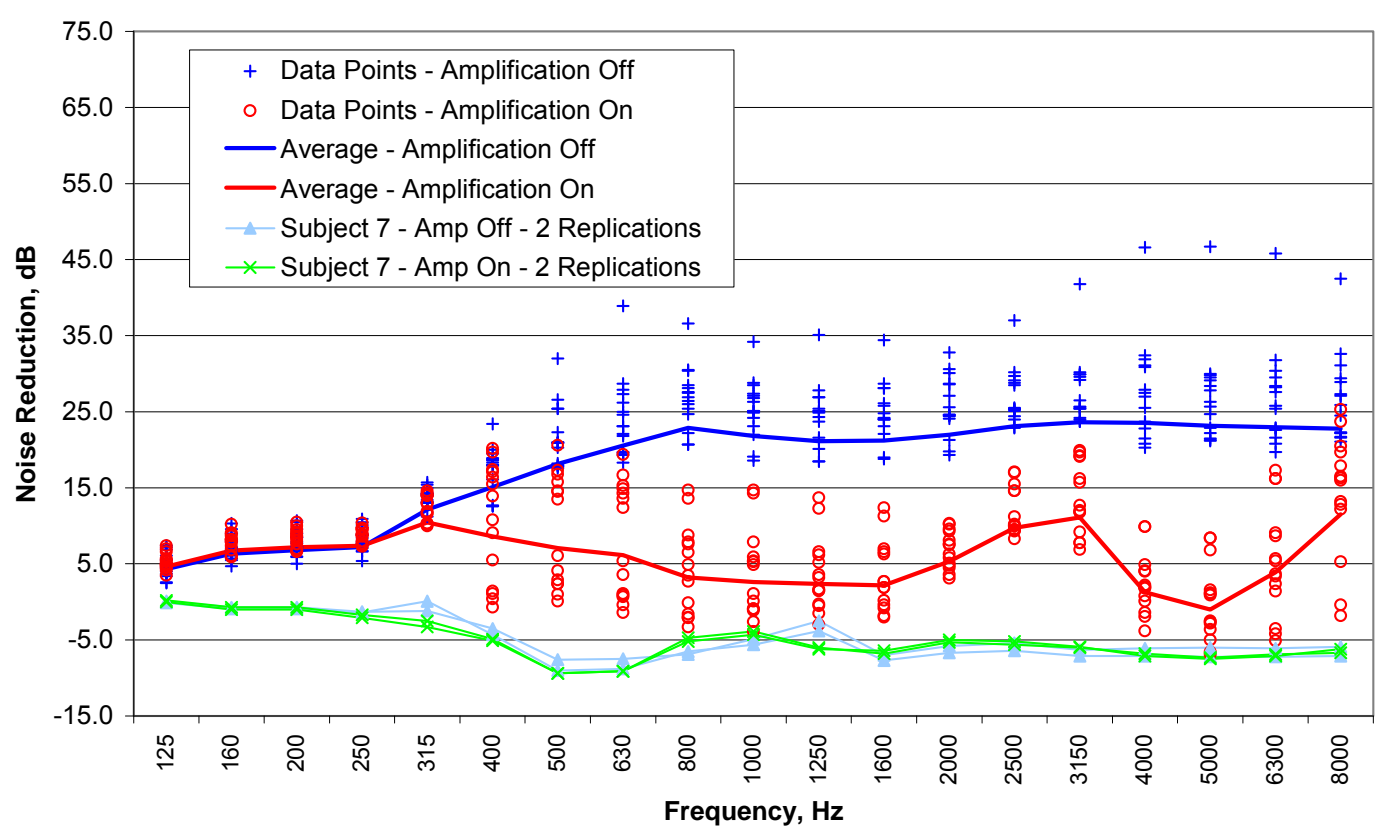

Figure B2. MSA Sordin Noise Reduction: Study Data vs. Manufacturer - Headset Amplification Off (With Subject 7)

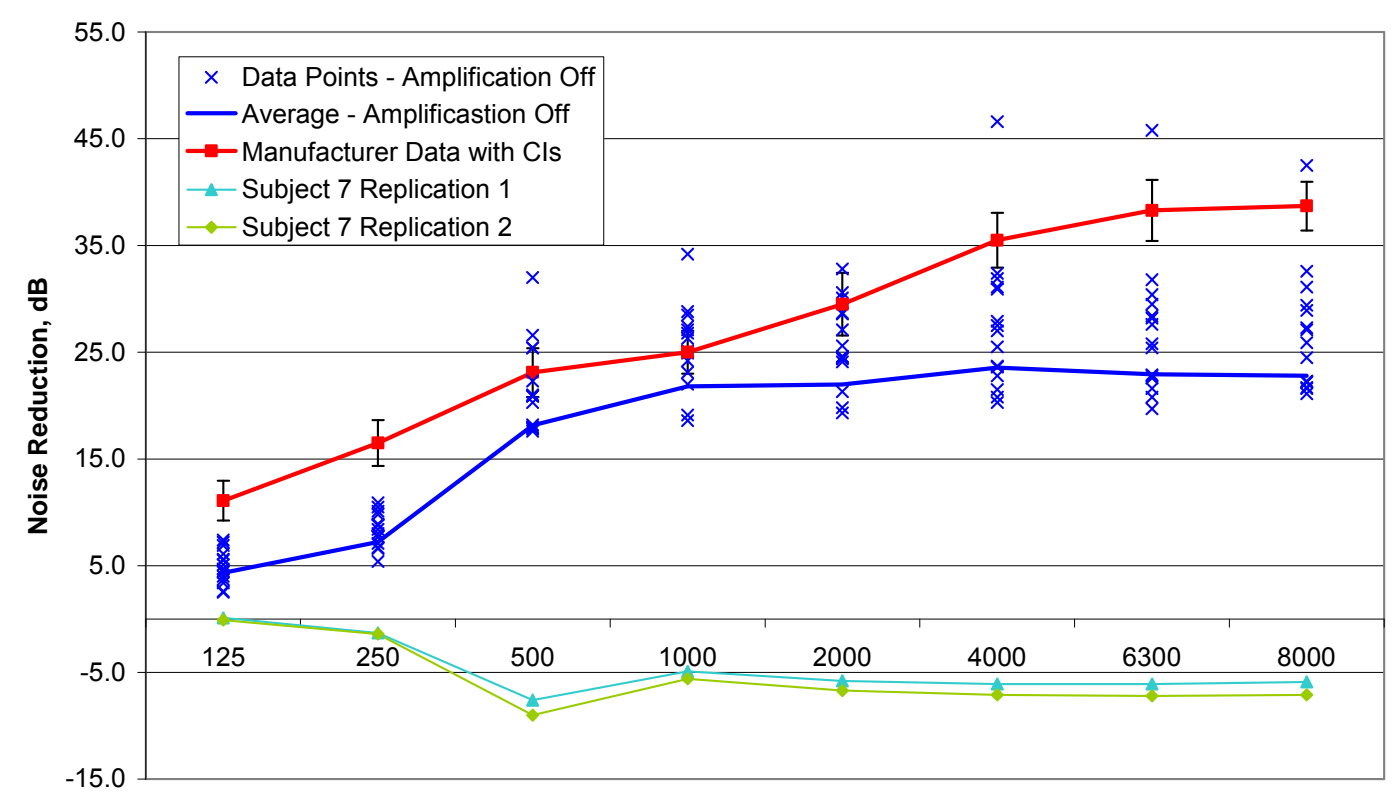

Frequency, $\mathrm{Hz}$ 
Table B1. Noise Reduction Values in Pink Noise Spectrum

\begin{tabular}{|l|c|c|c|c|c|}
\hline & \multicolumn{3}{|c|}{ Noise Reduction Measure } \\
\hline Hearing Protector & Linear & C-weigthed & A-weighted & OB $_{98}$ & NRR \\
\hline MSA Sordin Headset (Manufacturer) & 18.6 & 18.1 & 26.8 & 20.5 & 18.1 \\
\hline BCCS MSA Sordin Headset (Off) & 12.1 & 11.8 & 19.3 & -1.2 & -3.4 \\
\hline BCCS MSA Sordin Headset (On) & 4.5 & 4.6 & 3.6 & -9.0 & -11.2 \\
\hline & & & & & \\
Peltor Twin Cup H10A (Manufacturer) & 29.1 & 28.6 & 37.8 & 33.2 & 30.5 \\
\hline Peltor Twin Cup H10A & 22.9 & 22.6 & 32.4 & 23.2 & 21.1 \\
\hline
\end{tabular}

Table B2. Noise Reduction Values in Field Measured 47 footMLB Noise Spectrum

\begin{tabular}{|l|l|l|l|l|l|}
\hline \multicolumn{4}{|l|}{ Noise Reduction Measure } & \\
\hline Hearing Protector & Linear & C-weigthed & A-weighted & OB $_{98}$ & \\
\hline MSA Sordin Headset (Manufacturer) & 12.2 & 12.0 & 19.4 & 14.0 & \\
\hline MSA Sordin Headset (Off) & 6.3 & 6.3 & 10.2 & -0.6 & \\
\hline MSA Sordin Headset (On) & 6.2 & 6.2 & 5.5 & -7.2 & \\
\hline Peltor Twin Cup H10A (Manufacturer) & 22.1 & 22.0 & 29.5 & 25.5 & \\
\hline Peltor Twin Cup H10A & 16.6 & 16.6 & 21.0 & 16.8 & \\
\hline & & & & & \\
\hline
\end{tabular}

Table B3. Statistical Analysis of Overall Attenuation Values - MSA Sordin Headset, Amplification Off (with Subject 7)

\begin{tabular}{|c|c|c|c|c|c|c|c|c|c|c|c|c|c|}
\hline \multicolumn{10}{|c|}{ Low Frequency Noise Spectrum (47 footMLB) } & \multirow{2}{*}{\multicolumn{3}{|c|}{$\begin{array}{l}\text { Two-Sample Pooled T- } \\
\text { Test }\end{array}$}} & \multirow[b]{3}{*}{ Reject Null } \\
\hline & \multicolumn{2}{|c|}{ Manufacturer } & \multicolumn{4}{|c|}{ Study } & \multicolumn{3}{|c|}{$\mathrm{CI}$ for $\mathrm{x}_{1}-\mathrm{x}_{2}$} & & & & \\
\hline NR Value & $\mathrm{x}_{1}$ & $\mathrm{~s}_{1}{ }^{*}$ & $\mathrm{x}_{2}$ & $\mathrm{~s}_{2}$ & $\mathrm{~s}_{\mathrm{p}}$ & PE & LCL & UCL & $\mathrm{LCL}>0$ & $t_{\text {critical }}$ & $\mathrm{t}_{\text {actual }}$ & $\mathrm{P}_{\text {value }}$ & \\
\hline NR Linear & 12.2 & 3.2 & 6.1 & 3.2 & 3.2 & 6.1 & 4.3 & 7.9 & $\mathrm{Y}$ & 1.7 & 5.7 & $9.8 \mathrm{E}-07$ & $\mathrm{Y}$ \\
\hline NR C-Weighted & 12.0 & 3.2 & 6.1 & 3.2 & 3.2 & 5.9 & 4.1 & 7.7 & $\mathrm{Y}$ & 1.7 & 5.6 & $1.2 \mathrm{E}-06$ & $\mathrm{Y}$ \\
\hline NR A-Weighted & 19.4 & 5.5 & 9.3 & 5.5 & 5.5 & 10.1 & 7.1 & 13.2 & $\mathrm{Y}$ & 1.7 & 5.6 & $1.2 \mathrm{E}-06$ & $\mathrm{Y}$ \\
\hline & $\mathrm{n} 1=$ & 20 & & & & & & $\mathrm{H} 0: \mathrm{x} 1-\mathrm{x} 2$ & & & & & \\
\hline & $\mathrm{n} 2=$ & 17 & & & & & & $\mathrm{H} 1: \mathrm{x} 1-\mathrm{x} 2$ & $>0$ & & & & \\
\hline & $\mathrm{v}=$ & 35 & & & & & & alpha $=$ & 0.05 & & & & \\
\hline & alpha $=$ & 0.1 & & & & & & tcritical $=$ & 1.690 & & & & \\
\hline & $\mathrm{t}=$ & 1.690 & & & & & & & & & & & \\
\hline
\end{tabular}

* Variance for the manufacturer is assumed to equal that of the study data. Because overall NR values were calculated there is no available variance data for the manufacturer. 


\section{Appendix C. Hearing in Noise Test Sentence Lists}

List 1

1. $(\underline{\mathrm{A} / \text { the }})$ boy fell from (a/the $)$ window.

2. (A/the) wife helped her husband.

3. Big dogs can be dangerous.

4. Her shoes (are/were) very dirty.

5. (A/the) player lost ( $\underline{\mathrm{a}} / \mathrm{the})$ shoe.

6. Somebody stole the money.

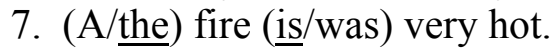

8. She's drinking from her own cup.

9. $(\mathrm{A} / \underline{\text { the }})$ picture came from $(\underline{\mathrm{a}} / \mathrm{the})$ book.

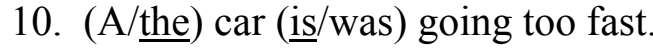

\section{List 2}

1. ( $\underline{\mathrm{A} / \text { the }})$ boy ran down (a/the) path.

2. Flowers grow in $(\mathrm{a} / \mathrm{the})$ garden.

3. Strawberry jam (is/was) sweet.

4. (A/the) shop closes for lunch.

5. The police helped (a/the) driver.

6. She looked in her mirror.

7. $(\mathrm{A} / \underline{\text { the }})$ match fell on (a/the) floor.

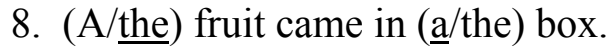

9. He really scared his sister.

10. (A/the) tub facet (is/was) leaking.

\section{List 3}

1. They heard ( $\underline{\mathrm{a}} /$ the) funny noise.

2. He found his brother hiding.

3. $(\mathrm{A} / \underline{\text { the }})$ dog played with $(\underline{\mathrm{a}} / \mathrm{the})$ stick.

4. $(\mathrm{A} / \underline{\text { the }})$ book tells (a/the) story.

5. The matches (are/where) on (a/the) shelf.

6. The milk (is/was) by (a/the) front door.

7. $(\mathrm{A} / \underline{\text { the }})$ broom (is/was) in (a/the $)$ corner.

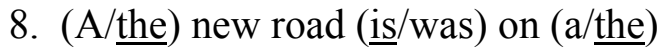
map.

9. She lost her credit card.

10. $(\mathrm{A} / \underline{\text { the }})$ team (is/was) playing well.

\section{List 4}

1. $(\mathrm{A} / \underline{\text { the }})$ little boy left home.

2. They're going out tonight.
3. $(\underline{\mathrm{A}} /$ the $)$ cat jumped over $(\mathrm{a} / \underline{\text { the }})$ fence.

4. He wore his yellow shirt.

5. (A/the) lady sits in her chair.

6. He needs his vacation.

7. She's washing her new silk dress.

8. (A/the) cat drank from (a/the) saucer.

9. Mother opened (a/the) drawer.

10. (A/the) lady packed her bag.

List 5

1. (A/the) boy did (a/the) handstand.

2. They took some food outside.

3. The young people (are/were) dancing.

4. They waited for an hour.

5. The shirts (are/were) in (a/the) closet.

6. They watched (a/the) scary movie.

7. The milk (is/was) in (a/the) pitcher.

8. (A/the) truck drove up (a/the) road.

9. (A/the) tall man tied his shoes.

10. $(\underline{\mathrm{A} / \text { the }})$ letter fell on $(\mathrm{a} / \underline{\mathrm{the}})$ floor.

List 6

1. (A/the) silly boy (is/was) hiding.

2. $(\mathrm{A} / \underline{\text { the }})$ dog growled at the neighbors.

3. $(\underline{\mathrm{A} / \text { the }})$ tree fell on $(\mathrm{a} / \mathrm{the})$ house.

4. Her husband brought some flowers.

5. The children washed the plates.

6 . They went on vacation.

7. Mother tied $(\mathrm{a} / \underline{\text { the }})$ string too tight.

8. (A/the) mailman shut (a/the) gate.

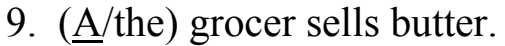

10. (A/the $)$ baby broke his cup.

List 7

1. The cows ( $\underline{\text { are }} /$ were $)$ in (a/the $)$ pasture.

2. (A/the) dishcloth (is/was) soaking wet.

3. They (have/had) some chocolate pudding.

4. She spoke to her oldest son.

5. (An/the) oven door (is/was) open.

6. She's paying for her bread.

7. My mother stirred her tea. 
8. He broke his leg again.

9. (A/the) lady wore ( $\underline{\mathrm{a}} /$ the $)$ coat.

10. The cups ( $\underline{\text { are } / w e r e) ~ o n ~(a / t h e) ~ t a b l e . ~}$

\section{List 8}

1. $(\mathrm{A} / \underline{\text { the }})$ ball bounced very high.

2. Mother cut (a/the) birthday cake.

3. (A/the) football game (is/was) over.

4. She stood near $(\mathrm{a} / \mathrm{the})$ window.

5. (A/the) kitchen clock (is/was) wrong.

6. The children helped their teacher.

7. They carried some shopping bags.

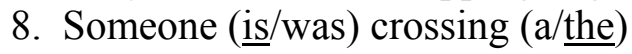

road.

9. She uses her spoon to eat.

10. $(\mathrm{A} / \underline{\underline{t h e}})$ cat lays on $(\mathrm{a} / \underline{\text { the }})$ bed.

List 9

1. School got out early today.

2. $(\mathrm{A} / \underline{\underline{\text { the }}})$ football hit (a/the) goalpost.

3. (A/the) boy ran away from school.

4. Sugar (is/was) very sweet.

5. The two children (are/were) laughing.

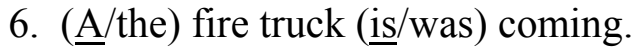

7. Mother got ( $\underline{a} /$ the $)$ sauce pan.

8. (A/the) baby wants his bottle.

9. (A/the) ball broke (a/the) window.

10. There (is/was) a bad train wreck.

List 10

1. $(\mathrm{A} / \underline{\text { the }})$ boy broke (a/the) wooden fence.

2. (An/the) angry man shouted.

3. Yesterday he lost his hat.

4. (A/the) nervous driver got lost.

5. (A/the) cook (ㅍs/was) baking (a/the) cake.

6. $(\mathrm{A} / \underline{\text { the }})$ chicken laid some eggs.

7. $(\underline{\mathrm{A}} / \mathrm{the})$ fish swam in (a/the) pond.

8. They met some friends at dinner.

9. $(\mathrm{A} / \underline{\text { the }})$ man called the police.

10. $(\mathrm{A} / \underline{\text { the }})$ truck made it up (a/the) hill.

\section{List 11}

1. (A/the) neighbor's boy (has/had)

black hair.
2. The rain came pouring down.

3. (An/the) orange (is/was) very sweet.

4. He took the dogs for a walk.

5. Children like strawberries.

6. Her sister stayed for lunch.

7. (A/the) train (is/was) moving fast.

8. Mother shut (a/the) window.

9. (A/the) bakery (is/was) open.

10. Snow falls in the winter.

List 12

1. (A/the) boy went to bed early.

2. (A/the) woman cleaned her house.

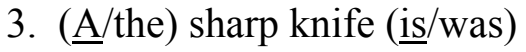
dangerous.

4. (A/the) child ripped open (a/the) bag.

5. They had some cold cuts for lunch.

6. She's helping her friend move.

7. They ate $(\mathrm{a} / \underline{\mathrm{the}})$ lemon pie.

8. They (are/were) crossing (a/the) street.

9. The sun melted the snow.

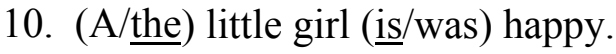

List 13

1. She found her purse in (a/the) trash.

2. (A/the) table (has/had) three legs.

3. The children waved at (a/the) train.

4. Her coat (is/was) on (a/the) chair.

5. (A/the) girl (is/ $\underline{\text { was }})$ fixing her dress.

6. It's time to go to bed.

7. Mother read the instructions.

8. (A/the) dog (ㅁs/was) eating some meat.

9. Father forgot the bread.

10. $(\mathrm{A} / \underline{\text { the }})$ road goes up ( $\underline{\mathrm{a}} / \mathrm{the})$ hill.

List 14

1. The fruit (is/was) on the ground.

2. They followed (a/the) garden path.

3 . They like orange marmalade.

4. There (are/were) branches everywhere.

5. (A/the) kitchen sink (is/was) empty.

6. The old gloves (are/were) dirty.

7. The scissors (are/were) very sharp. 
8. (A/the $)$ man cleaned his suede shoes.

9. (A/the) raincoat (is/was) dripping wet.

10. It's getting cold in here.

\section{List 15}

1. (A/the) house (has/had) nine bedrooms.

2. They're shopping for school clothes.

3. They're playing in $(\mathrm{a} / \mathrm{the})$ park.

4. Rain is good for the trees.

5. They sat on ( $\underline{a} /$ the $)$ wooden bench.

6. (A/the) child drank some fresh milk.

7. (A/the $)$ baby slept all night.

8. (A/the) salt shaker (is/ $\underline{\text { was }}$ ) empty.

9. (A/the $)$ policeman knows the way.

10. The buckets fill up quickly.

\section{List 16}

1. He played with his toy train.

2. They're watching ( $\underline{\mathrm{a}} / \mathrm{the})$ cuckoo clock.

3. Potatoes grow in the ground.

4. $(\mathrm{A} / \underline{\text { the }})$ girl ran along $(\mathrm{a} / \underline{\text { the }})$ fence.

5. (A/the $)$ dog jumped on (a/the) chair.

6. They finished dinner on time.

7. He got mud on his shoes.

8. They're clearing (a/the) table.

9. Some animals sleep on straw.

10. The police cleared $(\mathrm{a} / \underline{\text { the }})$ road.

\section{List 17}

1. Mother picked some flowers.

2. (A/the) puppy played with (a/the) ball.

3. (An/the) engine (is/was) running.

4. (An/the) old woman (is/was) at home.

5. They're watching (a/the) train go by.

6. (An/the) oven (is/was) too hot.

7. They rode their bicycles.

8. (A/the) big fish got away.

9. They laughed at his story.

10. They walked across the grass.

List 18

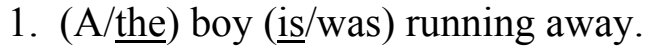

2. $(\mathrm{A} / \underline{\text { the }})$ towel (is/was) near (a/the $)$ sink.

3. Flowers can grow in ( $\underline{a} /$ the $)$ pot.

4. He's skating with his friend.

5. $(\mathrm{A} / \underline{\text { the }})$ janitor swept $(\mathrm{a} / \underline{\text { the }})$ floor.

6. (A/the $)$ lady washed $(\mathrm{a} / \underline{\mathrm{the}})$ shirt.

7. She took off her fur coat.

8. The match boxes (are/were) empty.

9. (A/the) man (모/was) painting (a/the) sign.

10. $(\mathrm{A} / \underline{\text { the }})$ dog came home at last.

\section{List 19}

1. (A/the) painter uses ( $\underline{\mathrm{a}} / \mathrm{the})$ brush.

2. (A/the) family bought ( $\underline{\mathrm{a}} /$ the) house.

3. Swimmers can hold their breath.

4. She cut $(\mathrm{a} / \mathrm{the})$ streak with her knife.

5. They're pushing an old car.

6. The food (is/was) expensive.

7. The children (are/were) walking home.

8. They (have/had) two empty bottles.

9. Milk comes in (a/the) carton.

10. $(\mathrm{A} / \underline{\text { the }})$ dog sleeps in $(\underline{\mathrm{a}} /$ the $)$ basket.

List 20

1. (A/the) clown (has/had) a funny face.

2. The bath water (is/was) warm.

3. She injured four of her fingers.

4. He paid his bill in full.

5. They stared at (a/the) picture.

6. (A/the) driver started (a/the) car.

7. (A/the $)$ truck carries fresh fruit.

8. (A/the) bottle (is/was) on the shelf.

9. The small tomatoes (are/were) green

10. (A/the) dinner plate (is/was) hot.

List 21

1. They're running past (a/the) house.

2. He's washing his face with soap.

3. (A/the) dog's chasing (a/the) cat.

4. (A/the) milkman drives ( $\underline{\mathrm{a} / \text { the }})$ small truck.

5. (A/the $)$ bus leaves before (a/the $)$ train.

6. (A/the) baby has blue eyes. 
7. (A/the) bag fell off (a/the) self.

8. They (are/were) coming for dinner.

9. They wanted some potatoes.

10. They knocked on (a/the) window.

\section{List 22}

1. $(\underline{\mathrm{A}} / \mathrm{the})$ girl came into (a/the) room.

2. ( $\underline{\mathrm{A}} /$ the $)$ field mouse found $(\mathrm{a} / \mathrm{the})$ cheese.

3. They're buying some fresh bread.

4. (A/the) machine (is/was) noisy.

5. (A/the) rice pudding (is/was) ready.

6. They had a wonderful day.

7. (An/the) exit (is/was) well lit.

8. (A/the) train stops at (a/the) station.

9. He (is/was) sucking his thumb.

10. (A/the) big boy kicked the ball.

\section{List 23}

1. The paint dripped on the ground.

2. (A/the) towel fell on (a/the) floor.

3. (A/the) family likes fish.

4. The bananas (are/were) too ripe.

5. He grew lots of vegetables.

6. She argues with her sister.

7. (A/the) kitchen window (is/was)

clean.

8. He hung up his raincoat.

9. (A/the) mailman brought ( $(\mathrm{a} /$ the $)$

letter.

10. $(\mathrm{A} / \underline{\text { the }})$ mother heard (a/the) baby.

\section{List 24}

1. (A/the) waiter brought (a/the) cream.

2. (A/the) teapot (is/was) very hot.

3. (An/the) apple pie (is/was) good.

4. (A/the) jelly jar (is/was) full.

5. (A/the) girl (is/was) washing her hair.

6. (A/the) girl played with (a/the) baby.

7. (A/the) cow (is/was) milked every

day.

8. They called an ambulance.

9. They (are/were) drinking coffee.

10. He climbed up (a/the) ladder.

\section{List 25}

1. (A/the) boy slipped on the stairs.

2. New neighbors (are/were) moving in.

3. (A/the) girl caught (a/the) head cold.

4. His father will come home soon.

5. (A/the) bus stopped suddenly.

6. He (is/was) washing his car.

7. (A/the) cat caught (a/the) little mouse.

8. They broke all the brown eggs.

9. (A/the) candy shop (is/was) empty.

10. (A/the) lady went to (a/the) store. 